\title{
A trans-diagnostic perspective on obsessive-compulsive disorder
}

\author{
C. M. Gillan ${ }^{1,2,3 *}$, N. A. Fineberg ${ }^{4,5}$ and T. W. Robbins ${ }^{2,3}$ \\ ${ }^{1}$ Department of Psychology, New York University, New York, NY, USA \\ ${ }^{2}$ Department of Psychology, University of Cambridge, Cambridge, UK \\ ${ }^{3}$ Behavioural and Clinical Neuroscience Institute, University of Cambridge, Cambridge, UK \\ ${ }^{4}$ National Obsessive Compulsive Disorders Specialist Service, Hertfordshire Partnership NHS University Foundation Trust, UK \\ ${ }^{5}$ Department of Postgraduate Medicine, University of Hertfordshire, Hatfield, UK
}

Progress in understanding the underlying neurobiology of obsessive-compulsive disorder (OCD) has stalled in part because of the considerable problem of heterogeneity within this diagnostic category, and homogeneity across other putatively discrete, diagnostic categories. As psychiatry begins to recognize the shortcomings of a purely symptombased psychiatric nosology, new data-driven approaches have begun to be utilized with the goal of solving these problems: specifically, identifying trans-diagnostic aspects of clinical phenomenology based on their association with neurobiological processes. In this review, we describe key methodological approaches to understanding OCD from this perspective and highlight the candidate traits that have already been identified as a result of these early endeavours. We discuss how important inferences can be made from pre-existing case-control studies as well as showcasing newer methods that rely on large general population datasets to refine and validate psychiatric phenotypes. As exemplars, we take 'compulsivity' and 'anxiety', putatively trans-diagnostic symptom dimensions that are linked to well-defined neurobiological mechanisms, goal-directed learning and error-related negativity, respectively. We argue that the identification of biologically valid, more homogeneous, dimensions such as these provides renewed optimism for identifying reliable genetic contributions to OCD and other disorders, improving animal models and critically, provides a path towards a future of more targeted psychiatric treatments.

Received 3 March 2016; Revised 4 October 2016; Accepted 4 October 2016; First published online 27 March 2017

Key words: ERN, goal-directed, OCD, RDoC, trans-diagnostic.

\section{Introduction}

The mainstay of psychiatric research is the case-control methodology whereby a group of individuals meeting the criteria for a disorder defined by the Diagnostic and Statistical Manual of Mental Disorders, 5th edn (DSM-5; APA, 2013) is compared to a group of healthy controls. Although the DSM has proven extremely useful in establishing a reliable psychiatric nosology that can be applied in a systematic way across centres (Regier et al. 2013), and that has led to the widespread development of evidence-based treatments, it has been suggested that shortcomings in the use of these categories for basic research are at least partly responsible for the lack of specific and robust associations between psychopathology and underlying neurobiological processes (Hyman, 2007; Sanislow et al. 2010).

Obsessive-compulsive disorder (OCD), is a chronic, costly and disabling brain disorder for which existing

\footnotetext{
* Address for correspondence: Dr C. M. Gillan, Department of Psychology, New York University, 6 Washington Place, New York, NY 10003, USA.

(Email: Claire.gillan@gmail.com)
}

treatments usually produce disappointing outcomes (Fineberg et al. 2014). It is defined in DSM-5 (APA, 2013) by the presence of obsessions and/or compulsions that are time consuming, distressing or disabling. Obsessions are repetitive thoughts, urges or images that are intrusive and unwanted, and that in most individuals cause anxiety or distress, for example recurrent thoughts about accidental death. They are associated with attempts by the individual to suppress or neutralize them with a compulsion. Compulsions are repetitive mental or overt acts that are experienced as being urge-driven either in response to an obsession or according to a rule that must be rigidly applied, and that are aimed at preventing or reducing anxiety or distress or preventing a feared event from happening. However, the compulsion either is not connected in a realistic way with the outcome it is designed to prevent, or is clearly excessive, such as a driver retracing their route to check for signs of an accident after experiencing a minor bump in the road.

DSM-5 acknowledges that these symptoms are not unique to OCD; outlining 14 other disorders (or disorder classes) whose symptoms also broadly fit these criteria, which the clinician must consider in the

This is an Open Access article, distributed under the terms of the Creative Commons Attribution licence (http://creativecommons.org/licenses/by/4.0/), which permits unrestricted re-use, distribution, and reproduction in any medium, provided the original work is properly cited. 
context of differential diagnosis. These disorders include other members of the obsessive-compulsive and related disorders family, in which obsessions and compulsions are focused either on bodily appearance (body dysmorphic disorder), grooming (trichotillomania and skin picking disorder) or the acquisition of and/or inability to discard personal items (hoarding disorder). Eating disorders are also characterized by behaviours that resemble obsessions and compulsions focused around body size and weight, whereas patients with generalized anxiety disorder (GAD) and depressive disorders experience intrusive, distressing ruminations that are similar to obsessions but are respectively focused on future or past mishaps. In the case of addictive disorders, the urge-driven addictive behaviours become increasingly rigid, stereotyped and compulsive over time, as their function changes from reward-seeking to preventing or neutralizing the distress associated with craving and withdrawal (Everitt et al. 2001).

In OCD, the level of insight varies considerably from good to absent both between patients and within the same patient over time. Poor insight has been associated with treatment resistance (Jacob et al. 2014). Intrusive, irrational thoughts frequently accompany schizophrenia spectrum and other psychotic disorders, and it can be difficult to distinguish obsessions from delusions, based on phenomenology alone. Moreover, approximately $30 \%$ of schizophrenia cases report obsessive-compulsive symptomatology and $14 \%$ have been found to have OCD (Swets et al. 2014). Some other individuals develop OCD symptoms as a result of environmental factors such as Paediatric Autoimmune Neuropsychiatric Disorder Associated with Streptococcus (PANDAS; Snider \& Swedo, 2003).

Even after careful attempts at differential diagnosis of OCD, co-morbidity is present in the majority of cases (Ruscio et al. 2010). Other psychiatric disorders, including anxiety, somatoform, impulse control, trauma-related, substance use, and personality disorders, are very common among patients with OCD and can affect adherence and response to treatment (Pallanti et al. 2011; Torres et al. 2016). Approximately three quarters of individuals with OCD in an epidemiological sample experienced either an anxiety disorder or an affective disorder (Fineberg et al. 2013a). Most forms of co-morbidity increase distress and impact negatively on family and work relationships, however, disorder-specific effects have also been observed. For example, agoraphobia and GAD were associated with increased OCD severity; bipolar disorder was associated with suicidal acts and panic disorder increased treatment-seeking behaviour (Fineberg et al. 2013a). In the case of selective serotonin re-uptake inhibitor (SSRI)-resistant OCD, a preferential effect for treatment with dopamine antagonists was seen for those with co-morbid tics (Bloch et al. 2006). These findings indicate quite clearly that these and other disorders are not discrete entities, and that the lines between different DSM diagnoses are often blurred (Fig. 1).

The issue of homogeneity across diagnostic categories is coupled with a related problem, heterogeneity within diagnostic categories. In the case of OCD, there is a mosaic of diverse phenomenological manifestations (Torres, 2016). A number of authors have attempted to group these phenomenological variables into a smaller number of relatively homogeneous, temporally stable symptom dimensions, using factor analysis of large symptom datasets. This has produced a multidimensional model of OCD that includes symmetry/ordering, hoarding, contamination/cleaning, and obsessions/checking) (Mataix-Cols et al. 2005; van den Heuvel et al. 2009). The authors propose these symptom dimensions should be understood as a spectrum of potentially overlapping syndromes that may (1) co-exist in any patient, (2) be continuous with normal obsessive-compulsive phenomena, and (3) extend beyond OCD. Although twin studies suggest there might be a genetic influence on dimension-specific risk (van Grootheest et al. 2008; Iervolino et al. 2011), the neurobiological validity of most of these factors has been difficult to demonstrate, owing to, for example, the lack of cross-study consistency of brain structural abnormalities associated with the various subtypes (Pujol et al. 2004; van den Heuvel et al. 2009; Alvarenga et al. 2012; de Wit et al. 2014). The hoarding dimension has proven very useful however, showing a consistently worse response to treatment than other forms of OCD (Mataix-Cols et al. 1999; Cullen et al. 2007). This particularly impactful finding has provoked a change in DSM-5, such that hoarding symptoms no longer exclusively contribute to a diagnosis of OCD, and are additionally captured by a separate category, 'hoarding disorder'. Unfortunately, hoarding symptoms do not account for all of the heterogeneity of treatment response in OCD, where for example one meta-analysis determined that the number needed to treat varied from 6-12 for SSRIs compared to placebo (Soomro et al. 2008).

The noisy response to treatment that remains to be bridged is likely to be a result of mechanistic heterogeneity within the OCD population that we cannot easily identify by analysing symptoms alone. In response, some researchers have called for a shift away from the use of DSM categories, in favour of establishing new and biologically relevant trans-diagnostic traits that may play an important role in multiple disorders, as we currently define them (Robbins et al. 2012; Cuthbert \& Kozak, 2013). The goal of such an 

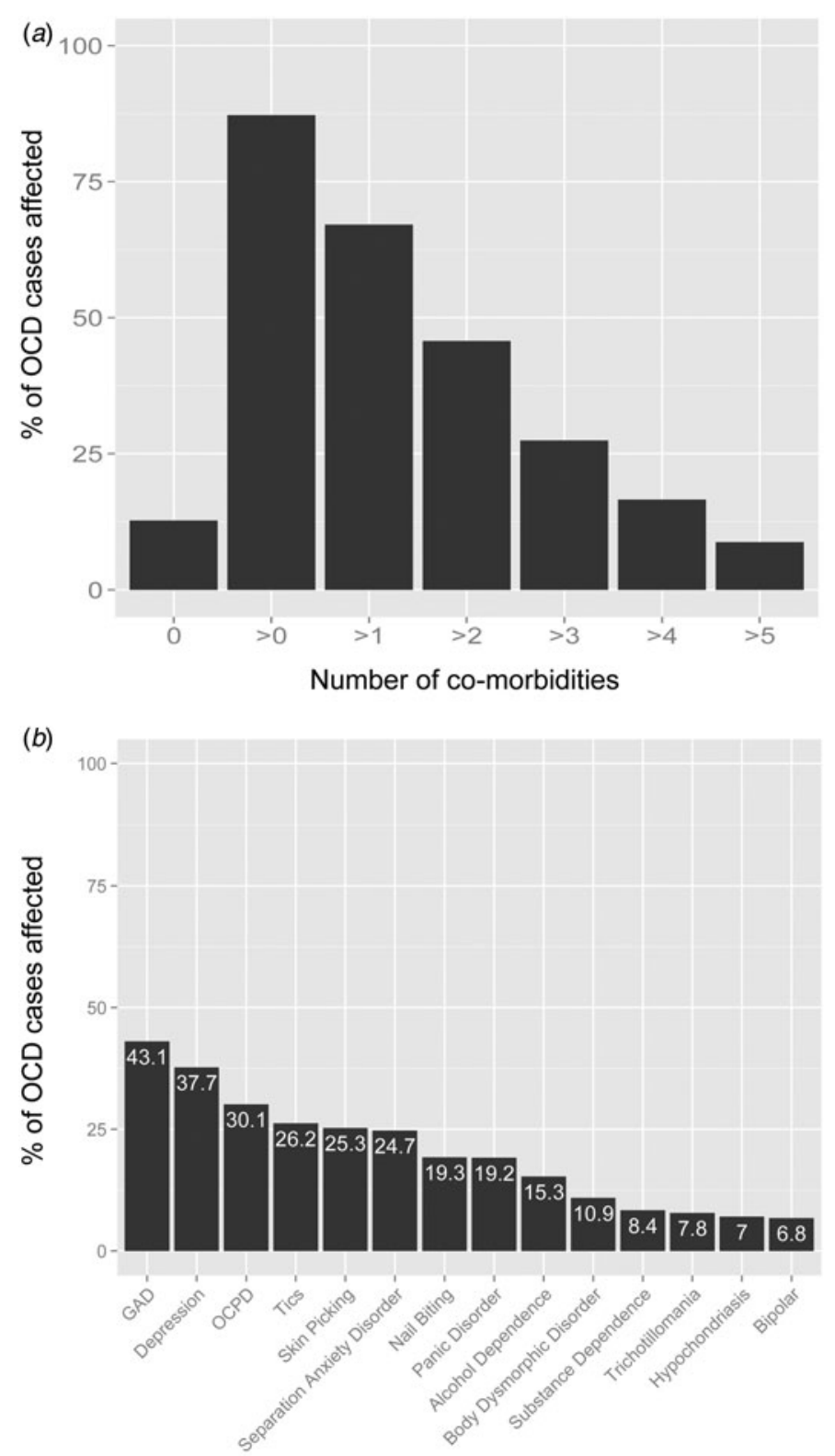

\section{Co-morbid disorders}

Fig. 1. Data from 706 obsessive-compulsive disorder (OCD) patients re-plotted with permission from Nestadt and colleagues (2009). Disorders assessed were obsessive-compulsive personality disorder (OCPD), generalized anxiety disorder (GAD), major depression (recurrent), tics, pathological skin picking, separation anxiety disorder, pathological nail biting, panic disorder, alcohol dependence, body dysmorphic disorder, substance dependence, trichotillomania, hypochondriasis, bipolar disorder. (a) Co-morbidity rates in a sample of OCD cases $-87.3 \%$ of patients met the criteria for another DSM diagnosis (note: this figure is probably higher as only select diagnoses were assessed). (b) The prevalence of specific co-morbid disorders within the OCD cohort.

enterprise is to permit evidence-based drug discovery, the development of robust animal models, and eventually realize a future of precision medicine in psychiatry. In a wider context, improved nosology based on more objective tests and criteria would lead to more homogeneous populations of patients for clinical trials, more accurate phenotypes for psychiatric genetics, and the potential for detection of early vulnerability, allowing for early therapeutic interventions that prevent progression to chronic illness.

The National Institute of Mental Health (NIMH) has been an important leader in this regard, launching its Research Domain Criteria (RDoC) initiative (Insel et al. 2010), a framework based on the premise that 
clinical constructs should be defined (and therefore investigated) on the basis of their neurobiological validity. This review will outline such a trans-diagnostic framework for understanding the DSM-5 diagnosis of OCD, outlining putative traits that link genes, molecules, cells, circuits, physiology, behaviour, self-reports and paradigms to clinical phenomenology. The goal is to highlight how a trans-diagnostic approach can shed light on some key puzzles in OCD research, and in so doing showcase the value that can be derived from existing case-control investigations and how this can inform newer attempts at trans-diagnostic psychiatry. Structurally, we will draw heavily on the NIMH's RDoC concepts and criteria, but acknowledge that other new initiatives such as the Roadmap for Mental Health Research (ROAMER) is promoting a similar trans-diagnostic approach (Goschke, 2014). More broadly, we hope to convey the importance of bridging the old with the new. RDoC should be applauded for its focus on biological reality, but perhaps goes too far by ignoring symptom-based approaches entirely. In psychiatry, the symptoms cause the suffering and our focus should remain on understanding and reducing these symptoms, as the patient experiences them.

\section{Case-control studies point to trans-diagnostic mechanisms in OCD: error-related negativity (ERN) and anxiety}

Can OCD be better understood and treated from a dimensional perspective? Evidence for this comes from many sources (Hyman, 2010); of these, perhaps the most compelling (and frustrating) is the lack of specificity of various neurocognitive deficits observed in OCD (Endrass \& Ullsperger, 2014; Fineberg et al. 2014). For example, 'response inhibition', the ability to cancel a prepotent motor response assayed using the stop-signal reaction-time task (Logan, 1994), is reliably impaired in not just OCD, but also attention deficit hyperactivity disorder (ADHD) and schizophrenia (Lipszyc \& Schachar, 2010). Pessimistically, one might conclude from this lack of specificity that our current neurocognitive markers are not useful for understanding the aetiology of OCD. Perhaps these markers reflect generalized executive impairment, a consequence of having any psychiatric disorder and the burdens thereof. Perhaps these markers are not diagnostic of any specific mental health issue, but simply place individuals into an at-risk state for many. What we will consider in the following sections is an admittedly well-trodden alternative: that it is our psychiatric taxonomy, not our neurocognitive models, that presents a problem for research and that the specificity of any neurocognitive model of a psychiatric diagnosis is fundamentally limited by the extent to which that diagnosis is biologically valid.

How can we determine if a neurocognitive model is specific to a trans-diagnostic phenotype, if not one of the existing DSM disorder categories? What does this mean for interpreting the results of prior work in these DSM diagnosed patient populations? A reasonable starting point is to first identify a model of biological relevance (e.g. neurocognitive or physiological marker) that exhibits partial specificity for psychiatric disorders that is perhaps not specific to one disorder, but certainly not common to all. One can then qualitatively identify phenotypic commonalities across the disorders that exhibit mechanistic commonalities and thus formulate hypotheses about trans-diagnostic phenotypes (Robbins et al. 2012; Fineberg et al. 2014). Publication bias is an obstacle here as studies showing no difference between patient cohorts and controls, which are needed to make a case for specificity, are less likely to be published or even submitted for publication (Rosenthal, 1979). One solution (albeit imperfect) to this problem is studying multiple disorders at once, thereby allowing for direct statistical comparison of disorders that have established deficits in a given domain and disorders that are hypothesized to be no different from controls. Failing this, one can gain insights by leveraging cases where a given neurocognitive mechanism is significantly enhanced in one cluster of disorders, but deficient in another (thereby avoiding publication bias), as is the case for one very promising neurocognitive deficit in OCD that we will discuss in some detail, ERN (Endrass \& Ullsperger, 2014).

The ERN is a negative deflection of the eventrelated potential (ERP) when subjects make an error (Falkenstein et al. 1991), listed as the RDoC subconstruct 'Performance Monitoring'. It is typically measured using electroencephalogram, but functional imaging has been coupled with this technique to confirm that the ERN has its source in the anterior cingulate cortex (ACC) (Debener et al. 2005). A host of studies have found enhanced ERN in OCD (Gehring et al. 2000; Johannes et al. 2001b; Ruchsow et al. 2005, 2007; Endrass et al. 2008, 2010, 2014; Hajcak et al. 2008; Stern et al. 2010; Riesel et al. 2011, 2015; Xiao et al. 2011; Hanna et al. 2012; Carrasco et al. 2013a, b; Grützmann et al. 2014; Klawohn et al. 2014; Liu et al. 2014) (but see Nieuwenhuis et al. 2005; Agam et al. 2014; Mathews et al. 2015; Weinberg et al. 2015), GAD (Ladouceur et al. 2006; Weinberg et al. 2012, 2015, 2010) (but see Xiao et al. 2011), social anxiety disorder (Endrass et al. 2014) and depression (Chiu \& Deldin, 2007; Holmes \& Pizzagalli, 2008, 2010; Georgiadi et al. 2011; Aarts et al. 2013; Tang et al. 2013; Mueller et al. 2015) (although less consistently than in generalized anxiety or OCD, see Ruchsow et al. 2004, 2006; 
Olvet et al. 2010; Georgiadi et al. 2011; Weinberg et al. 2012) (Table 1). Accounts regarding the precise function of ERN are varied (Holroyd \& Coles, 2002; Yeung et al. 2004), but studies have shown that the ERN primes defensive responses, for example by potentiating startle responses (Hajcak \& Foti, 2008) and encouraging avoidance behaviour (Frank et al. 2005). Together with a qualitative examination of the symptom commonalities across these disorders, this suggests that anxiety might be a reasonable candidate for consideration as a dimensional phenotype related to these deficits. This thesis is supported by work in non-clinical samples, wherein the magnitude of the ERN is associated with self-reported worry (Hajcak et al. 2003; Zambrano-Vazquez \& Allen, 2014), high levels of trait anxiety (Paulus et al. 2004) and OC-symptoms (Hajcak \& Simons, 2002; ZambranoVazquez \& Allen, 2014). The effect appears to be trait (rather than state) dependent; the ERN remains enhanced following successful treatment in both adult and paediatric OCD (Hajcak et al. 2008; Riesel et al. 2015), does not differ as a result of chronic medication (Stern et al. 2010) and an enhanced ERN has been observed in unaffected first-degree relatives of both adult and paediatric OCD sufferers (Riesel et al. 2011; Carrasco et al. 2013a), suggesting that this may be an important endophenotype that predisposes individuals to a range of disorders that involve anxiety.

Critically, the postulate that an enhanced ERN is a useful marker of an anxious phenotype rests on the specificity of this effect. We can begin to, albeit imperfectly, approach this issue using existing work in diagnosed patients - specifically if enhanced ERN is observed in disorders not in part characterized by pathological anxiety, then this suggests there is more evidence for the pessimistic view suggested earlier. Fortunately, evidence for such specificity is abundant for this particular neurocognitive marker; a large body of work has showed that a significantly decreased ERN magnitude is characteristic of a putatively distinct cluster (or clusters) of disorders, most consistently schizophrenia (Kopp \& Rist, 1999; Alain et al. 2002; Bates et al. 2002, 2004; Morris et al. 2006, 2008, 2011; Mathalon et al. 2009; Foti et al. 2012; Horan et al. 2012; Perez et al. 2012; Simmonite et al. 2012; Houthoofd et al. 2013; Kansal et al. 2014; Minzenberg et al. 2014; de la Asuncion et al. 2015; Reinhart et al. 2015), but also bipolar disorder (Minzenberg et al. 2014; Morsel et al. 2014) (but see Kopf et al. 2015), autism spectrum disorders (Vlamings et al. 2008; Sokhadze et al. 2010, 2012; South et al. 2010) (but see Groen et al. 2008; Henderson et al. 2015) and various forms of addiction (Forman et al. 2004; Franken et al. 2007; Sokhadze et al. 2008; Luijten et al. 2011; Zhou et al. 2013) (but see Schellekens et al. 2010; Chen et al.
2013). Moreover, the amplitude of the ERN was found to predict treatment adherence for substance abuse (Steele et al. 2014) and decreases in the ERN are associated with self-reported impulsivity (Potts et al. 2006). Results in ADHD are mixed with some studies showing decreased ERN (Liotti et al. 2005; van Meel et al. 2007; Groen et al. 2008; Herrmann et al. 2010; Groom et al. 2013), but most reporting no differences (Wiersema et al. 2005, 2009; Groen et al. 2008; Wild-Wall et al. 2009; Zhang et al. 2009; Groom et al. 2010; Sokhadze et al. 2012) and only one study reporting an increase (Burgio-Murphy et al. 2007) (Table 1). Together, these data provide convergent evidence that an enhancement of the ERN is not ubiquitous in psychiatry, but rather appears to be directionally specific to disorders characterized predominantly by anxiety. This therefore may constitute a trans-diagnostic marker relevant for many disorders involving anxiety, including OCD.

\section{Validating a trans-diagnostic mechanism: goal-directed learning and compulsivity}

The suggestion that the consistent finding of enhanced ERN in OCD in fact reflects a trans-diagnostic phenotype representing anxiety is perhaps a compelling one given the pattern of results described above. However, without direct comparison across disorders and/or discrete symptom dimensions, conclusions regarding its phenomenological specificity cannot be drawn (indeed 'anxiety' is intended to serve as a placeholder, until such work is complete). We will now highlight an approach that can take this next step, drawing on data from an independent line of research in OCD. This body of research centres on the theory that an imbalance between 'goal-directed control' and 'habit-learning' drives symptoms in OCD (see Gillan \& Robbins, 2014 for detailed account) (see Supplementary material), such that compulsive behaviours in OCD are not goal-directed responses to anxiety/perceived threat, but are in fact stimulus-evoked, goal-insensitive habits (Dickinson, 1985). This model suggests that compulsions are not a search for safety; they are a result of the need to realize a link that has developed between a stimulus or context and a given set of responses. In this view, the subjective experiences that accompany habits, such as 'not just right experience' (Coles et al. 2005; Ecker \& Gönner, 2008), or more complex obsessive thoughts are the result of the compulsive urge, not the cause. For example, there is preliminary evidence to suggest that obsessive thoughts can even arise as a result of compulsive habit formation in OCD, and not the other way around (Gillan et al. 2014b; Gillan \& Sahakian, 2015), constituting a sharp divergence from most cognitive models of OCD that focus on obsessive thoughts (Salkovskis, 
Table 1. Summary of results for studies examining error-related negativity (ERN) across psychiatric disorders

\begin{tabular}{|c|c|c|c|c|}
\hline & Unmedicated $^{\mathrm{a}}$ & $\mathrm{ERN}^{\mathrm{b}}$ & Sample size (case, control) & Task \\
\hline \multicolumn{5}{|l|}{ Obsessive-compulsive disorder } \\
\hline Gehring et al. (2000) & & $\uparrow$ & 9,9 & Stroop \\
\hline Johannes et al. (2001b) & $x$ & $\uparrow$ & 10,10 & Cued RT task \\
\hline Ruchsow et al. (2005) & & $\uparrow$ & 11,11 & Go/NoGo \\
\hline Nieuwenhuis et al. (2005) & & N.s. & 16,16 & Probabilistic RL \\
\hline Endrass et al. (2008) & & $\uparrow$ & 20,20 & Flanker \\
\hline Hajcak et al. $(2008)^{c}$ & & $\uparrow$ & 18,18 & Simon \\
\hline Endrass et al. (2010) & & $\uparrow$ & 22,22 & Flanker \\
\hline Endrass et al. (2010) & & N.S. & 22,22 & Flanker \\
\hline Stern et al. $(2010)^{\mathrm{d}}$ & & $\uparrow$ & 38,40 & Flanker \\
\hline Xiao et al. $(2011)^{\mathrm{e}}$ & & $\uparrow$ & 25,27 & Flanker \\
\hline Riesel et al. (2011) & & $\uparrow$ & 30,30 & Flanker \\
\hline Hanna et al. $(2012)^{c}$ & & $\uparrow$ & 44,44 & Flanker \\
\hline Carrasco et al. $(2013 a)^{\mathrm{c}}$ & & $\uparrow$ & 40,40 & Flanker \\
\hline Carrasco et al. $(2013 b)^{\mathrm{c}, \mathrm{e}, \mathrm{f}}$ & & $\uparrow$ & 26,27 & Flanker \\
\hline Endrass et al. $(2014)^{\mathrm{e}}$ & & $\uparrow$ & 24,24 & Flanker \\
\hline Grützmann et al. (2014) & & $\uparrow$ & 20,22 & Flanker \\
\hline Agam et al. (2014) & & N.s. & 19,16 & Antisaccade task \\
\hline Klawohn et al. (2014) & & $\uparrow$ & 26,26 & Flanker \\
\hline Liu et al. $(2014)^{c}$ & & $\uparrow$ & 20,20 & Flanker \\
\hline Mathews et al. $(2015)^{\mathrm{e}}$ & & N.S. & 27,45 & Flanker \\
\hline (Riesel et al. (2015) & & $\uparrow$ & 41,37 & Flanker \\
\hline Weinberg et al. $(2015)^{\mathrm{e}}$ & & N.s. & 26,56 & Flanker \\
\hline \multicolumn{5}{|l|}{ Generalized anxiety disorder } \\
\hline Ladouceur et al. (2006) & $x$ & $\uparrow$ & 9,10 & Flanker \\
\hline Weinberg et al. (2010) & $x$ & $\uparrow$ & 17,24 & Flanker \\
\hline Xiao et al. $(2011)^{\mathrm{e}}$ & & N.s. & 27,27 & Flanker \\
\hline Weinberg et al. $(2012)^{\mathrm{e}}$ & $x$ & $\uparrow$ & 26,36 & Flanker \\
\hline Carrasco et al. $(2013 b)^{\mathrm{c}, \mathrm{e}, \mathrm{f}}$ & & $\uparrow$ & 13,27 & Flanker \\
\hline Weinberg et al. $(2015)^{\mathrm{e}}$ & & $\uparrow$ & 57,56 & Flanker \\
\hline \multicolumn{5}{|l|}{ Depression } \\
\hline Ruchsow et al. (2004) & & N.s. & 16,16 & Flanker \\
\hline Ruchsow et al. (2006) & & $\downarrow$ & 10,10 & Go/NoGo \\
\hline Chiu \& Deldin (2007) & & $\uparrow$ & 18,17 & Flanker \\
\hline Holmes \& Pizzagalli (2008) & $\times$ & $\uparrow \uparrow$ & 20,20 & Stroop \\
\hline Olvet et al. (2010) & $x$ & N.S. & 22,22 & Flanker \\
\hline Holmes \& Pizzagalli (2010) & $\times$ & $\uparrow$ & 18,18 & Stroop \\
\hline Georgiadi et al. $(2011)^{\mathrm{g}}$ & & $\uparrow$ & 19,19 & Go/NoGo \\
\hline Georgiadi et al. (2011) & & N.S. & 17,17 & Go/NoGo \\
\hline Ladouceur et al. $(2012)^{\mathrm{c}}$ & $x$ & $\downarrow$ & 24,14 & Flanker \\
\hline Aarts et al. (2013) & & $\uparrow$ & 20,20 & Go/NoGo \\
\hline Tang et al. (2013) & $x$ & $\uparrow$ & 22,24 & Flanker \\
\hline Mueller et al. (2015) & $x$ & $\uparrow$ & 14,15 & Probabilistic RL \\
\hline Weinberg et al. $(2015)^{\mathrm{e}}$ & & N.S. & 62,56 & Flanker \\
\hline \multicolumn{5}{|l|}{ Other anxiety disorders } \\
\hline Clemans et al. (2012) [PTSD] & & $\downarrow$ & 10,10 & Flanker \\
\hline Rabinak et al. (2013) [PTSD] & $x$ & N.s. & 16,16 & Flanker \\
\hline Endrass et al. (2014) [social] $]^{\mathrm{e}}$ & & $\uparrow$ & 24,24 & Flanker \\
\hline \multicolumn{5}{|l|}{ Hoarding disorder } \\
\hline Mathews et al. (2015) ${ }^{\mathrm{e}}$ & & $\downarrow$ & 14,45 & Flanker \\
\hline \multicolumn{5}{|l|}{ Schizophrenia } \\
\hline Kopp \& Rist (1999) & & $\downarrow$ & 29,18 & Flanker \\
\hline
\end{tabular}


Table 1 (cont.)

\begin{tabular}{|c|c|c|c|c|}
\hline & Unmedicated $^{\mathrm{a}}$ & $\mathrm{ERN}^{\mathrm{b}}$ & Sample size (case, control) & Task \\
\hline Alain et al. (2002) & & $\downarrow$ & 12,12 & Stroop \\
\hline Bates et al. (2002) & & $\downarrow$ & 21,21 & Go/NoGo \\
\hline Bates et al. (2004) & & $\downarrow$ & 9,9 & Go/NoGo \\
\hline Morris et al. (2006) & & $\downarrow$ & 16,11 & Flanker \\
\hline Morris et al. (2008) & & $\downarrow$ & 26,27 & Probabilistic RL \\
\hline Mathalon et al. (2009) & & $\downarrow$ & 11,10 & Go/NoGo \\
\hline Morris et al. (2011) & & $\downarrow$ & 20,15 & Flanker \\
\hline Foti et al. $(2012)^{\mathrm{e}}$ & & $\downarrow$ & 33,33 & Flanker \\
\hline Simmonite et al. $(2012)^{\mathrm{h}}$ & & $\downarrow$ & 29,35 & Go/NoGo \\
\hline Horan et al. (2012) & & $\downarrow$ & 16,14 & Flanker \\
\hline Perez et al. $(2012)^{\mathrm{h}}$ & & $\downarrow$ & 84,110 & Matching \\
\hline Houthoofd et al. (2013) & & $\downarrow$ & 12,12 & Flanker \\
\hline Kansal et al. (2014) & & $\downarrow$ & 18,18 & Stroop \\
\hline Minzenberg et al. $(2014)^{\mathrm{e}}$ & & $\downarrow$ & 73,54 & Stroop \\
\hline de la Asuncion et al. (2015) & & $\downarrow$ & 22,21 & Simon \\
\hline Reinhart et al. (2015) & & $\downarrow$ & 19,18 & Probabilistic RL \\
\hline \multicolumn{5}{|l|}{ Bipolar disorder } \\
\hline Minzenberg et al. (2014) & & $\downarrow$ & 26,54 & Stroop \\
\hline Kopf et al. (2015) & & N.S. & 20,18 & Flanker \\
\hline Morsel et al. (2014) & & $\downarrow$ & 16,14 & Flanker \\
\hline \multicolumn{5}{|l|}{ Addiction } \\
\hline Forman et al. (2004) [opiates] & & $\downarrow$ & 13,26 & Go/NoGo \\
\hline Chen et al. (2013) [opiates] & & N.s. & 17,15 & Flanker \\
\hline Franken et al. (2007) [cocaine] & $x$ & $\downarrow$ & 14,13 & Flanker \\
\hline Sokhadze et al. (2008) [cocaine] & & $\downarrow$ & 6,6 & Flanker \\
\hline Schellekens et al. (2010) [alcohol] & & $\uparrow$ & 29,15 & Flanker \\
\hline Luijten et al. (2011) [nicotine] & $\times$ & $\downarrow$ & 13,14 & Flanker \\
\hline Zhou et al. (2013) [internet] & & $\downarrow$ & 23,23 & Flanker \\
\hline \multicolumn{5}{|c|}{ Attention deficit hyperactivity disorder } \\
\hline Liotti et al. $(2005)^{c, i}$ & $\times$ & $\downarrow$ & 10,10 & Stop signal \\
\hline Wiersema et al. $(2005)^{c, i}$ & $\times$ & N.S. & 22,15 & Go/NoGo \\
\hline van Meel et al. (2007) & $x$ & $\downarrow$ & 16,16 & Flanker \\
\hline Jonkman et al. (2007) & $x$ & N.s. & 10,10 & Flanker \\
\hline Burgio-Murphy et al. $(2007)^{c, e, i}$ & $x$ & $\uparrow$ & 182,60 & Cued RT task \\
\hline Burgio-Murphy et al. $(2007)^{c, e}$ & $x$ & N.s. & 77,60 & Cued RT task \\
\hline Groen et al. $(2008)^{\mathrm{c}, \mathrm{e}, \mathrm{i}}$ & $\times$ & $\downarrow$ & 18,18 & Probabilistic RL \\
\hline Groen et al. $(2008)^{\mathrm{c}, \mathrm{e}, \mathrm{i}}$ & & $\downarrow$ & 17,18 & Probabilistic RL \\
\hline Wild-Wall et al. (2009) $)^{\mathrm{c}, \mathrm{i}}$ & & N.s. & 15,12 & Flanker \\
\hline Zhang et al. (2009) ${ }^{c}$ & & N.s. & 14,14 & Go/NoGo \\
\hline Wiersema et al. (2009) & & N.s. & 23,19 & Go/NoGo \\
\hline Groom et al. $(2010)^{\mathrm{c}, \mathrm{i}}$ & $x$ & N.s. & 23,19 & Go/NoGo \\
\hline Herrmann et al. $(2010)^{\mathrm{i}}$ & $x$ & $\downarrow$ & 34,34 & Flanker \\
\hline Sokhadze et al. $(2012)^{c, e}$ & & N.S. & 16,16 & Oddball \\
\hline Groom et al. $(2013)^{\mathrm{c}, \mathrm{i}}$ & $x$ & $\downarrow$ & 28,28 & Go/NoGo \\
\hline Groom et al. $(2013)^{\mathrm{c,i}}$ & & N.s. & 28,28 & Go/NoGo \\
\hline \multicolumn{5}{|l|}{ Autism spectrum disorders } \\
\hline Groen et al. $(2008)^{\mathrm{c}, \mathrm{e}}$ & $\times$ & N.S. & 18,18 & Probabilistic RL \\
\hline Vlamings et al. $(2008)^{c}$ & $x$ & $\downarrow$ & 17,10 & Matching \\
\hline South et al. $(2010)^{\mathrm{h}}$ & & $\downarrow$ & 24,21 & Flanker \\
\hline Sokhadze et al. $(2010)^{c}$ & & $\downarrow$ & 14,14 & Oddball \\
\hline Sokhadze et al. $(2012)^{\mathrm{c}, \mathrm{e}}$ & & $\downarrow$ & 16,16 & Oddball \\
\hline
\end{tabular}


Table 1 (cont.)

\begin{tabular}{|c|c|c|c|}
\hline Unmedicated $^{\mathrm{a}}$ & $\mathrm{ERN}^{\mathrm{b}}$ & Sample size (case, control) & Task \\
\hline Henderson et al. $(2015)^{\mathrm{c}}$ & N.S. & 38,36 & Flanker \\
\hline \multicolumn{4}{|c|}{$\begin{array}{l}\text { N.S., Non-significant; PTSD, post-traumatic stress disorder; RT, reaction time; RL, reinforcement learning. } \\
{ }^{a} \text { Unmedicated were free of selective serotonin re-uptake inhibitors or antipsychotics for at least } 2 \text { weeks, and free of } \\
\text { timulants for } 17 \mathrm{~h} \text {. In the case of addiction, unmedicated applies when subjects meet the above criteria and are abstinent. } \\
{ }^{b} \text { Studies were included if they reported results of ERN analysis (either ERN or ERN corrected for correct-related negativity), } \\
\text { acluded a case-control comparison, and reported generic ERN effects using a task that could be compared across studies. } \\
{ }^{c} \text { Paediatric/adolescent sample. } \\
{ }^{\mathrm{d}} \text { Compared medicated and unmedicated groups, and no medication effect was observed. } \\
{ }^{\text {e }} \text { Compared to other diagnoses in trans-diagnostic design. } \\
{ }^{\mathrm{f}} \text { Mixed anxiety (mostly generalized anxiety disorder). } \\
{ }^{\mathrm{g}} \text { Remitted patients. } \\
{ }^{\mathrm{h}} \text { Mixture adult and adolescent. } \\
{ }^{\mathrm{i}} \text { Attention deficit hyperactivity disorder combined-type only. }\end{array}$} \\
\hline
\end{tabular}

1985). The original habit hypothesis of OCD was based on a convergence of neurobiological data illustrating that the pathophysiology of OCD overlaps extensively with that supporting the balance between goaldirected behaviour and habits (Graybiel \& Rauch, 2000; Dolan \& Dayan, 2013). Empirical studies have found broad support for this idea; OCD patients show a reliable tendency to form habits excessively in both appetitive and aversive learning contexts (Gillan et al. 2011, 2014b). Based on convergent evidence from follow-up investigations utilizing neuroimaging and computational modelling (Gillan et al. 2014a, 2015a; Voon et al. 2014), the working model theorizes that deficits in goal-directed control, mediated by the caudate and medial orbitofrontal cortex, are responsible for the excessive habits observed in OCD in the laboratory (Gillan \& Robbins, 2014). Clinically, these habits might manifest as compulsive behaviours and/or higher-order habitual needs or goals (Cushman \& Morris, 2015).

Addressing the trans-diagnostic potential of this neurocognitive mechanism, goal-directed control has been suggested to play a role in a range of disorders that are clinically characterized by repetitive behaviours that persist despite negative events, or are experienced as 'out of control' (Gillan et al. 2016a). These disorders include addiction (Everitt \& Robbins, 2005), eating disorders (Godier \& Park, 2014) and Tourette's syndrome (Groenewegen et al. 2003), and although this area of research is still in its infancy, the first empirical investigations have found evidence for goal-directed deficits in these disorders (Sjoerds et al. 2013; Voon et al. 2014; Delorme et al. 2015; Ersche et al. 2016) (Table 2). As such, the candidacy of goal-directed deficits as a trans-diagnostic marker has been acknowledged in the RDoC matrix, which flags several relevant theoretical domains, i.e. 'Habit', 'Goal Selection, Updating, Representation and Maintenance' and 'Response Selection, Inhibition or Suppression'. However, studies have recently been published showing similar deficits in goal-directed control in schizophrenia (Morris et al. 2015), autism spectrum disorder (Alvares et al. 2016), and most problematically, social anxiety disorder (Alvares et al. 2014, 2016), which is not considered clinically to be a 'compulsive' disorder (Table 2).

Using a case-control design, it is difficult to disentangle a genuine lack of mechanistic specificity, as these data might indicate, from 'DSM measurement error', the confounding influence of co-morbid psychiatric disorders. For example, in the aforementioned studies in social anxiety disorder patients (Alvares et al. 2014, 2016), because patients presented with multiple co-morbid disorders, one cannot know if the results are attributable to social anxiety symptoms or one or more of their co-morbid conditions. Indeed, like most disorders, OCD rates are higher in the social anxiety population (Grant et al. 2005). To get around this issue, some researchers (ourselves included) have endeavoured to recruit only 'pure cases' of OCD, i.e. those that do not meet the criteria for any other psychiatric diagnoses (Table 2). Although somewhat effective, the problem with this approach is that it assumes that being one criterion short of diagnosis of depression, for example, is the same as having no depressive symptoms at all. In reality, OCD patients recruited in this way consistently have higher levels of subthreshold symptoms of multiple other disorders, e.g. depression and anxiety (Gillan et al. 2011). While these confounding variables could be controlled for 
Table 2. Summary of results for studies examining goal-directed learning

\begin{tabular}{|c|c|c|c|c|}
\hline & Unmedicated $^{\mathrm{a}}$ & Goal-directed control & Sample size (case, control) & Task \\
\hline \multicolumn{5}{|l|}{ Obsessive compulsive disorder } \\
\hline Gillan et al. (2011) & & $\downarrow$ & 20,20 & Devaluation \\
\hline Gillan et al. (2014b) & & $\downarrow$ & 25,25 & Devaluation \\
\hline Gillan et al. (2014a) & & $\downarrow$ & 20,20 & A-O learning \\
\hline Voon et al. $(2014)^{\mathrm{b}}$ & $x$ & $\downarrow$ & 32,96 & MB learning \\
\hline Gillan et al. $(2015 a)^{c}$ & & $\downarrow$ & 37,33 & Devaluation \\
\hline \multicolumn{5}{|l|}{ Social anxiety disorder } \\
\hline Alvares et al. (2014) & & $\downarrow$ & 23,23 & Devaluation \\
\hline Alvares et al. $(2016)^{\mathrm{b}}$ & & $\downarrow$ & 20,19 & Devaluation \\
\hline \multicolumn{5}{|l|}{ Schizophrenia } \\
\hline Morris et al. (2015) & & $\downarrow$ & 18,18 & Devaluation \\
\hline \multicolumn{5}{|l|}{ Addiction } \\
\hline Sjoerds et al. (2013) [alcohol] & & $\downarrow$ & 31,19 & A-O learning \\
\hline Voon et al. (2014) [meth] ${ }^{\mathrm{b}}$ & & $\downarrow$ & 22,66 & MB learning \\
\hline Voon et al. (2014) [alcohol] $]^{\mathrm{b}}$ & $x$ & N.S. & 30,90 & MB learning \\
\hline Ersche et al. (2016) [cocaine] & & $\downarrow$ & 72,53 & Devaluation \\
\hline \multicolumn{5}{|l|}{ Tourette syndrome } \\
\hline Delorme et al. (2016) & $x$ & $\downarrow$ & 17,17 & Devaluation \\
\hline Delorme et al. (2016) & & N.s. & 17,17 & \\
\hline \multicolumn{5}{|l|}{ Autism spectrum disorders } \\
\hline Geurts \& de Wit (2013) ${ }^{\mathrm{d}}$ & & N.s. & 24,24 & Devaluation \\
\hline Alvares et al. (2016) & & $\downarrow$ & 17,19 & Devaluation \\
\hline \multicolumn{5}{|l|}{ Eating disorders } \\
\hline Voon et al. (2014) [binge eating] ${ }^{\mathrm{b}}$ & $x$ & $\downarrow$ & 31,93 & MB learning \\
\hline
\end{tabular}

N.s., Non-significant.

Goal-directed learning was measured using devaluation, model-based (MB) learning or action-outcome (A-O) learning test. The latter two measures are proxies for devaluation sensitivity (Gillan et al. 2011, 2015b).

${ }^{\text {a }}$ Unmedicated were free of selective serotonin re-uptake inhibitors or antipsychotics for at least 2 weeks, and free of stimulants for $17 \mathrm{~h}$. In the case of addiction, unmedicated applies when subjects meet the above criteria and are abstinent.

${ }^{\mathrm{b}}$ Compared multiple diagnostic groups.

${ }^{\mathrm{c}}$ Compared medicated and unmedicated groups, and no medication effect was observed.

${ }^{\mathrm{d}}$ Paediatric sample.

statistically, most patient studies simply do not have the necessary power to do so. Indeed, the difficulty in recruiting sufficient sample sizes for research studies with patients is compounded by the increasing number of (possibly confounding) disorders defined by the DSM in every new edition.

A novel solution to this problem was presented in a recent study that eschewed the traditional case-control design in favour of the greater sample sizes (and in turn statistical power) that can be achieved by leveraging normal variability in a large general population sample (Gillan et al. 2016b). The study tested if the relationship between goal-directed control and psychopathology constitutes a trans-diagnostic trait by testing its generalizability and specificity. Just under 2000 subjects were recruited online and completed selfreport questionnaires assessing multiple psychiatric symptoms and completed a web-based task that assessed goal-directed performance (i.e. 'model-based learning'; Daw et al. 2011). In line with the preceding case-control literature, normal variation in selfreported OCD symptomatology (Foa et al. 2002) was associated with decreases in goal-directed control in two separate samples collected in this study (also see a recent independent replication: Snorrason et al. 2016). Importantly, this effect was generalizable to symptoms of other aspects of compulsive psychopathology (as previously characterized in the literature: Everitt \& Robbins, 2005; Hogarth et al. 2012; Godier \& Park, 2014). Specifically, eating disorders (Garner et al. 1982), impulsivity (Patton et al. 1995) and alcohol addiction (Saunders et al. 1993) were also associated with deficits in goal-directed control, suggestive of a trans-diagnostic deficit linking these disorders. Crucially, these deficits were not associated with symptoms of trait anxiety (Spielberger et al. 1983), depression (Zung, 1965), social anxiety (Liebowitz, 1987) or apathy (Marin et al. 1991). Schizotypy 


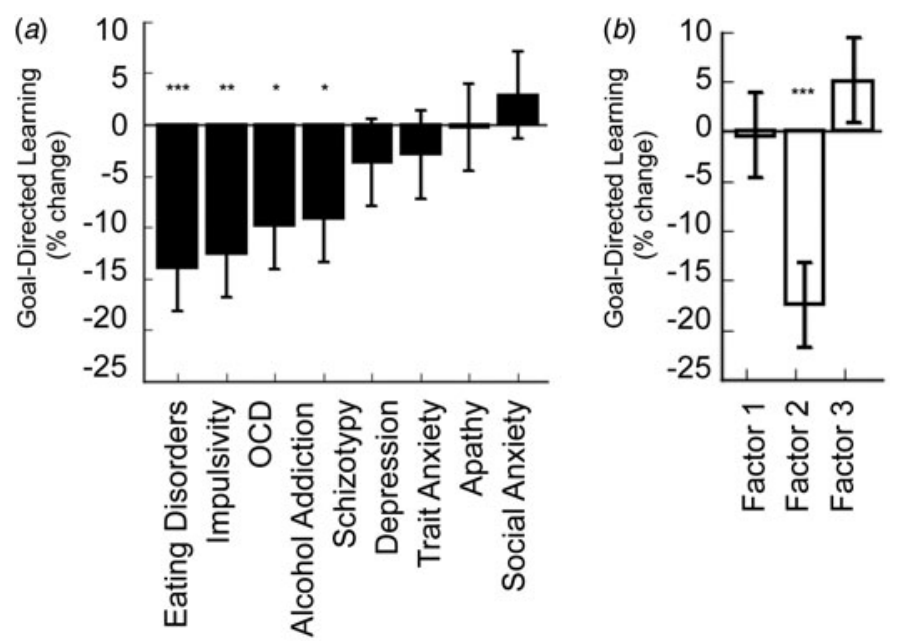

Fig. 2. Validating a trans-diagnostic dimension. (a) The strength of the association between self-report symptoms of various DSM disorders and deficits in goal-directed control. The pattern is strikingly non-specific. $(b)$ The association between goal-directed deficits and three 'trans-diagnostic symptom dimensions identified in a data-driven factor analysis. Factor 1 corresponds to 'Anxious Depression', Factor 2 is 'Compulsive Behavior and Intrusive Thought', and Factor 3 is 'Social Withdrawal'. The association between Factor 2 ('Compulsive Behavior and Intrusive Thought') and deficits in goal-directed learning is greater than that of any of the nine DSM-inspired questionnaires and crucially, the relationship exhibits excellent specificity with respect to 'non-compulsive' aspects of psychopathology, i.e. Factor 1 ('Anxious Depression') and Factor 3 ('Social Withdrawal'). Data reproduced with permission from Gillan et al. (2016b). ${ }^{*} p<0.05,{ }^{* *} p<0.01,{ }^{* * *} p<0.001$.

(Mason et al. 2005) sat somewhere in the middle, showing a marginal association with goal-directed deficits (Fig. 2a).

Although these results are suggestive of generalizability and specificity, this kind of analysis does not take us much further than work in diagnosed patients, save to say that these effects appear to be continuous in the general population rather than being specific to diagnosed groups. A more important question is what the psychiatric phenotype that explains this pattern of results? Is there a trans-diagnostic symptom dimension shared by some disorders (e.g. OCD, addiction, eating disorders), but not others (e.g. social anxiety, depression)? To answer this question empirically, this study employed a twostage validation methodology. First, a factor analysis was carried out on psychiatric self-report data to identify a smaller set of clinical phenotypes that more parsimoniously explain the self-report symptom data. This approach revealed that three factors could replace the nine original questionnaires and of particular interest was a factor linking disorders at the level of compulsive behaviour and thought, so-called 'Compulsive Behaviour and Intrusive Thought'. This factor comprised select features of OCD, eating disorders, addiction and some aspects of impulsivity and schizotypy that pertain to a loss of control over repetitive behaviour and thought. Next, this phenotype was tested for biological validity by assessing if subjects' scores on this factor predicted goal-directed performance in an independent analysis. 'Compulsive Behaviour and Intrusive Thought' was found to be more predictive of goal-directed deficits than any DSM-inspired questionnaire collected in this study (Fig. 2b), illustrating the power of data-driven clinical phenotyping. For example, this trans-diagnostic symptom dimension predicted task performance better than total scores on questionnaires measuring severity of DSM disorders such as OCD, eating disorders and addiction. Crucially, this relationship was dissociable from other trans-diagnostic phenotypes identified in this study, 'Anxious-Depression' and 'Social Withdrawal' (which showed no relation to goal-directed deficits), which could be compared directly in this study, providing compelling evidence for the specificity of this deficit to 'Compulsive Behaviour and Intrusive Thought'. This approach showcases how in an appropriately powered general population sample, a neurocognitive model can be tested for both generalizability and specificity, leading to a data-driven definition of a neurobiologically validated clinical phenotype.

\section{Going deeper: 'units of analysis'}

In tandem with new approaches to empirically define psychiatric phenotypes, the task for basic research is to delineate the neurobiology that underpins them. RDoC proposes that this should be done, where appropriate, using units of analysis that link clinical phenomenology (e.g. self-reports) to behaviour/physiology (via paradigms) to the underlying circuit, cells, molecules and finally, genes. The aims of this approach are to 


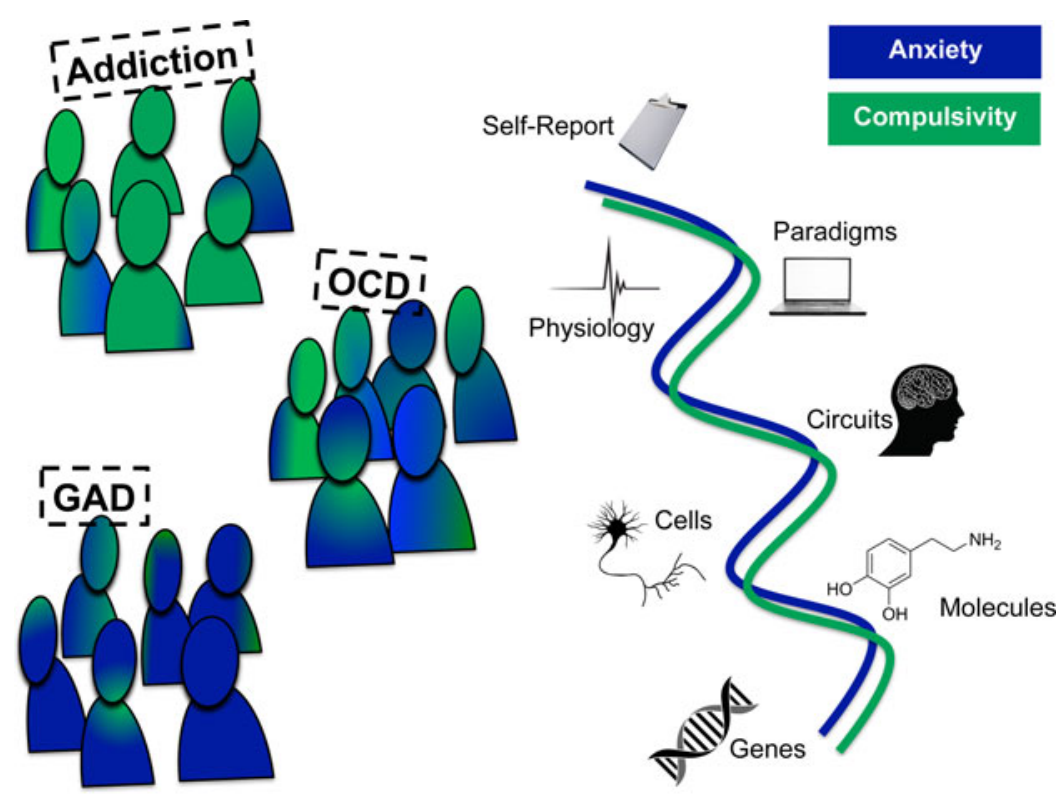

Fig. 3. A trans-diagnostic approach to obsessive-compulsive disorder (OCD). The predominant symptoms of OCD may result from complex interaction between independent trans-diagnostic dimensions, of which anxiety and compulsivity are good (but not the only) candidates. In this simplified schematic, we show just two putative trans-diagnostic psychiatric dimensions, there are of course many others. The task for basic research, outlined in the Research Domain Criteria initiative is to understand these dimensions at units of analysis, linking self-report symptoms (such as anxiety and compulsivity) to paradigms, physiology, circuits, cells, molecules and genes. GAD, Generalized anxiety disorder.

facilitate evidence-based drug-development (e.g. based on pharmacological underpinnings), to guide new therapeutic approaches such as psychological therapies (e.g. based on neurocognitive changes) or brain stimulation (e.g. based on knowledge of brain circuits), and to identify and treat those at risk (e.g. using genetic tests) (Fig. 3).

Here, we will highlight just a couple of examples drawing on units of analysis that have the most direct implications for treatment. Might the ERN be useful for deciding on which treatment to prescribe to which individual? To begin to answer this, we must review what is known about the pharmacology of the ERN (i.e. as a molecular unit of analysis). Benzodiazepines, specifically alprazolam (Riba et al. 2005), lorazepam (de Bruijn et al. 2004) and oxazepam (Johannes et al. 2001a), reduce the amplitude of the ERN. This suggests a potential role for GABA (which is thought to directly inhibit ACC functioning) in the ERN and with that, a putative biological basis for the therapeutic effect of these drugs for GAD and therefore plausibly also for anxiety as a trans-diagnostic trait (Ravindran \& Stein, 2010). Unfortunately, this theory runs into issues when one considers that benzodiazepines are ineffective for treating OCD (e.g. clonazepam, Hollander et al. 2003). Moreover, antidepressants, such as paroxetine and mirtazapine, which appear to have no effect on the ERN (de Bruijn et al. 2004, 2006), have good efficacy for treating both OCD and GAD. This apparent lack of pharmacological specificity is compounded by research on dopamine, which is probably been the most studied neurotransmitter with respect to the ERN. Studies in this area have shown that amphetamine administration increases the amplitude of the ERN (de Bruijn et al. 2004), while antipsychotics such as haloperidol and olanzapine reduce it (Zirnheld et al. 2004; de Bruijn et al. 2006). Although antipsychotics can be useful for OCD in particularly treatment resistant cases, GAD does not respond to antipsychotics (Ravindran \& Stein, 2010).

Thus, the question of how an ERN measurement can help inform treatment response across disorders is far from clear. It may be the case that combined measures, such as ERN, structural scans and self-report, are needed to produce a useful therapeutic signal. For example, although the core symptoms of OCD do not typically reduce following benzodiazepines, this drug class might be useful for decreasing anxiety in certain OCD patients - and these particularly anxious patients might be driving the ERN findings from studies examining this patient population at the group level. Alternatively, the ERN might have no specific causal role for psychiatry whatsoever, it might arise from a range of discrete upsets to neural harmony longitudinal designs are needed to answer these questions definitively. 
Turning to circuits, cells and the link between self-report compulsivity and deficits in goal-directed control (Gillan et al. 2016b), studies point to the involvement of the medial orbitofrontal cortex (mOFC) and caudate based on their involvement in goal-directed control across species (Dolan \& Dayan, 2013) and convergent data suggesting these are critically involved in OCD and other compulsive disorders. For example, hyperactivity in the caudate nucleus is linked to failures in goal-directed behaviour observed in OCD patients (Gillan et al. 2015a). In terms of brain structure, deficits in goal-directed control are associated with reductions of grey-matter volume in the caudate and $\mathrm{mOFC}$ in healthy individuals (Voon et al. 2014). Moreover, in this same study, the observation that these regional volumes are reduced in binge-eating disorder patients was statistically explained by their deficits of goaldirected control relative to controls (Voon et al. 2014). Although imaging studies in humans are important for validating animal models of psychiatric populations, animal models are crucial as they can uniquely assess causality (Ahmari, 2015). To this end, one exemplary study showed that chronic stimulation of mOFC neurons that project to the ventromedial striatum [i.e. mimicking the hyperactivity observed in human OCD patients (Gillan et al. 2015a)] induces compulsive grooming behaviour in mice (Ahmari et al. 2013). Furthermore, the authors found that excessive grooming was ameliorated with chronic SSRI treatment, the first line pharmacotherapy for OCD (Fineberg et al. 2013b), thereby showing convergence across multiple units of analysis, from behaviour to brain circuits to molecules. What remains to be seen is whether this kind of chronic stimulation also induces deficits in goaldirected control in tandem with compulsive grooming, and if deficits in goal-directed control are remediated by treatment with SSRIs. These are testable hypotheses that, if supported, could mean that computerized tasks that assess this neurocognitive mechanism might be used to inform treatment allocation in the future. In addition to guiding pharmacotherapy decisions, work at the circuit level can be used to select target sites for deep-brain stimulation, of which there are many candidates for OCD (Mallet et al. 2008; Nuttin et al. 2008; Denys et al. 2010; Greenberg et al. 2010) and indeed to guide the allocation of distinct forms of behavioural therapy (Saxena et al. 2009). The question of whether deficits in goal-directed control diminish with successful treatment (and are akin to state phenomena) or remain elevated and stable (trait) awaits investigation. But even more interesting in our minds is the question of whether or not goal-directed performance at baseline predicts better response to one treatment over another. This may be how the success of the marker should be ultimately judged.
Precision therapeutics: insights and trans-diagnostic opportunities

Although defining biologically valid clinical phenotypes as accurately and discretely as possible is valuable, it may not be the most important thing that trans-diagnostic psychiatry research can contribute. Even if a phenotype such as 'compulsivity' possesses good neurobiological validity, specificity and homogeneity, this may not translate into homogeneity of treatment response. Rather, discrete neural pathophysiology may give rise to common network-level dysfunctions and behavioural manifestations, and these distal phenotypic markers might therefore offer minimal insight for clinicians in deciding on whether or not an SSRI will be effective in an individual. One way to address this is to work from the bottom-up to take a step back from phenotypic classification and focus instead on establishing robust and direct links between neurocognitive markers and treatment response. This kind of work has already begun, typically within the confines of one diagnostic category or another and we will briefly mention some of the most promising data. We will take a particular focus on pharmacological interventions, but the general approach can similarly be applied to behavioural interventions. Then we will highlight how treatment prediction research involving sufferers of many DSM categories that are prescribed the same treatment is likely to be an important approach of the future.

Taking neural markers as an example, several studies have had early success at using functional imaging at the group level to predict treatment response within the OCD population (for review see Ball et al. 2014). One potential marker of SRI response in OCD is reduced baseline activity in the OFC and ACC (Swedo et al. 1992, 1989; Brody et al. 1998; Saxena et al. 1999). Unfortunately several studies that came later failed to replicate (Saxena et al. 2003; Carey et al. 2004; Ho Pian et al. 2005; van der Wee et al. 2007), finding no significant effects or in some cases entirely different neural markers. A recent study tested whether a task-related ACC measure like ERN might fare better than these resting studies at predicting clinical response. Although the result should be taken cautiously as the sample size was particularly small (only 10 patients returned at post-treatment assessment), the authors were unable to find a relationship between baseline ERN and cognitive behaviour therapy response in a paediatric OCD sample (Hajcak et al. 2008).

One possibility is that the predictive value of ACC activity (if there is any) could be exclusive to a putative anxiety dimension and this might get washed out in studies relying on heterogeneous diagnostic categories and small samples. Recruiting large samples across 
diagnostic categories and recording changes in the symptoms of dissociable psychiatric dimensions like anxiety and compulsivity might help isolate reliable effects. Indeed, in the one study that adopted a transdiagnostic approach, recruiting individuals with OCD, depression or both, the authors were able to identify dissociable neural markers of subsequent depressive $v$. obsessive-compulsive response to paroxetine (Saxena et al. 2003). This means that not only is the same drug effective in treating distinct psychiatric problems, its efficacy at treating depression and OCD symptoms (sometimes in the same individual) is predicted by dissociable patterns of abnormal baseline neural activity. Given that individuals with a diagnosis of OCD are aetiologically and phenotypically heterogeneous, the task for future research is not to identify mean baseline activity patterns in responders $v$. nonresponders on some singular measure of function, but to use large datasets to tease apart the mechanisms through which a given drug can reduce symptoms of largely independent psychiatric dimensions, and use these insights to identify the patients for whom a symptom reduction is likely to happen following treatment.

To conclude this section with some practical statements, morphometric predictors of SRI response in OCD already appear to be somewhat more robust than functional ones. The only two structural MRI studies to date have both shown that decreased grey matter in the lateral OFC is also linked to SRI response (Hoexter et al. 2013, 2015). Hoexter and colleagues showed that OFC grey-matter volume had $77 \%$ sensitivity and $81 \%$ specificity at predicting SRI response in OCD. If these figures hold up to replication using the same analysis pipeline, the interpretation is that if this marker were used to determine whether or not an SRI is prescribed to a drug-naive individual, just two out of every 10 people assigned to SSRI would not respond, while another two of the 10 not assigned the treatment would have missed out on the benefits of the SSRI (Hoexter et al. 2015). This would make it a useful tool for clinicians, were MRI scans not expensive and impractical for most clinics to use diagnostically (at least for now). This is where we suggest cognitive neuroscience might be able to intervene by replacing brain scans with cognitive tasks that are good indicators of neurobiology, such those linked to normal and pathological variation in OFC grey-matter volume, of which goal-directed control is one notable example (Voon et al. 2014). Cognitive behavioural therapy for OCD similarly might benefit from the addition of components that focus more directly on habit formation and goal-directed control in those patients for whom it is more relevant. For example, one might focus psychoeducation: patients could be taught about identifying habit 'trigger' situations, or identifying the development of new habits that might later develop into more elaborate compulsions. Alternatively, habit-reversal training (Snorrason et al. 2015) may be used to complement standard exposure and response prevention techniques. These behavioural treatments might be further enhanced with targeted pharmacotherapy, for which basic data are accruing (Lovinger, 2010).

\section{Combining trans-diagnostic with existing approaches}

We have argued strongly in favour of the transdiagnostic model as a rational approach to advance basic science research in psychiatry, but must make clear that to date this approach has yet to facilitate gene discovery or the development of new, better treatments. It will take time for sufficient data to accrue and as such, dismissing symptom-based approaches entirely is premature. Existing clinical trial datasets, based on patients grouped according to conventional diagnostic criteria such as DSM, have demonstrated a clear specificity of effect for certain psychiatric treatments [e.g. serotonin $v$. noradrenaline reuptake inhibitors in OCD (Fineberg et al. 2014)], and a magnitude of efficacy for some of our treatments commensurate with the effect sizes seen in other branches of medicine (Davis et al. 2011; Leucht et al. 2015). We have also seen that specific drug response can be linked to easily observable symptoms, such as the presence of tics (Bloch et al. 2006). The hope is that by revisiting how we define disorder and/or dimensions using biological and cognitive data will further enhance the precision with which treatments can be delivered to individuals. In addition, new ways of assessing the outcomes of treatment trials, e.g. using statistical techniques such as group-based mixture models, that divide 'diagnostic' patient samples into clinically meaningful subgroups with greater predictive value, hold promise for the advancement of personalized psychiatric treatment (Thase et al. 2011). Thus, most progress is likely to be made with a balanced approach, taking into account and if possible combining the most valid and reliable diagnostic and trans-diagnostic methodologies.

\section{Conclusion}

This paper presented a trans-diagnostic perspective on OCD - a diagnostic category - that selectively focused on just two putative mechanisms relevant for our understanding of anxiety and compulsivity in OCD. These candidate mechanisms illustrate how two orthogonal trans-diagnostic mechanisms might converge to produce a phenotype that is currently defined as a unitary category. Specifically, avoidance compulsions, obsessions and anxiety are the defining 
clinical features of OCD according to DSM-5 (APA, 2013). As the symptom complex that this triad produces is unlikely to be underpinned by one specific cognitive/neural mechanism, breaking OCD down into orthogonal trans-diagnostic mechanisms may be of benefit for developing translational models - particularly for animal models that are crucial for causal mechanistic investigations. This research initiative has just begun for OCD, and many candidate dimensions await empirical validation or rejection. This can be achieved in many different ways, just a few of which have been outlined here (see other good examples: Fair et al. 2012; Brodersen et al. 2014), and at many units of analysis. Most importantly, psychiatric diagnostic tools of the future must focus on maximizing predictive value, refining treatment allocation (both behavioural and pharmacological), identifying prospects and tools for early intervention, determining risk and clinical course. To do this, we need a new wave of focused longitudinal studies in psychiatry that can assess which cognitive tests or neural markers possess the most clinically useful properties. While studies of this kind have been historically difficult to conduct, costly and complicated, the field is already rising to the challenge by developing new methodologies (Brodersen et al. 2014; Gillan \& Daw, 2016) that will help us to put biological psychiatry to the clinical test.

\section{Supplementary material}

The supplementary material for this article can be found at https://doi.org/10.1017/S0033291716002786.

\section{Acknowledgements}

The authors thank Michael Evans for his contribution to the preparation of Tables 1 and 2. We also thank Gerald Nestadt and Jack Samuels for providing the data for Fig. 1 from their original paper (Nestadt et al. 2009). C.M.G. is supported by a Sir Henry Wellcome Postdoctoral Fellowship from the Wellcome Trust (101521/Z/12/Z). T.W.R. is supported by a Senior Investigator Award from the Wellcome Trust (106431/Z/14/Z).

\section{Declaration of Interest}

C.M.G. has no disclosures. N.A.F has received payment for consultancy from Servier, Lundbeck, GSK, AstraZeneca and Bristol-Myers Squibb, for research activities from Servier, Lundbeck, ECNP, MRC, NIHR, Wellcome and for educational activities from Shire, Otsuka, Lundbeck, Janssen, Bristol-Myers Squibb, Wyeth, Servier, College of Mental Health
Pharmacists, Royal College of Psychiatrists, Royal Australia and New Zealand College of Psychiatrists, BAP. T.W.R consults for Cambridge Cognition, E. Lilly , Lundbeck, Teva, Shire Pharmaceuticals, Otsuka. Research Grants; GSK, Lundbeck, Eli Lilly Inc. He receives royalties from Cambridge Cognition (CANTAB). He is an editor at Springer and Elsevier.

\section{References}

Aarts K, Vanderhasselt MA, Otte G, Baeken C, Pourtois G (2013). Electrical brain imaging reveals the expression and timing of altered error monitoring functions in major depression. Journal of Abnormal Psychology 122, 939-950.

Adams CD (1982). Variations in the sensitivity of instrumental responding to reinforcer devaluation. Quarterly Journal of Experimental Psychology, Section B: Comparative and Physiological Psychology 34, 77-98.

Agam Y, Greenberg JL, Isom M, Falkenstein MJ, Jenike E, Wilhelm S, Manoach DS (2014). Aberrant error processing in relation to symptom severity in obsessive-compulsive disorder: a multimodal neuroimaging study. Neuroimage: Clinical 5, 141-151.

Ahmari S, Spellman T, Douglass N, Kheirbek M, Simpson H, Deisseroth K, Gordon J, Hen R (2013). Repeated cortico-striatal stimulation generates persistent OCD-like behavior. Science 340, 1234-1239.

Ahmari SE (2015). Using mice to model obsessive compulsive disorder: from genes to circuits. Neuroscience.

Alain C, McNeely HE, He Y, Christensen BK, West R (2002). Neurophysiological evidence of error-monitoring deficits in patients with schizophrenia. Cerebral Cortex 12, 840-846.

Alvarenga PG, do Rosário MC, Batistuzzo MC, Diniz JB, Shavitt RG, Duran FL, Dougherty DD, Bressan RA, Miguel EC, Hoexter MQ (2012). Obsessive-compulsive symptom dimensions correlate to specific gray matter volumes in treatment-naïve patients. Journal of Psychiatry Research 46, 1635-1642.

Alvares GA, Balleine BW, Guastella AJ (2014). Impairments in goal-directed actions predict treatment response to cognitive-behavioral therapy in social anxiety disorder. PLoS ONE 9, e94778.

Alvares GA, Balleine BW, Whittle L, Guastella AJ (2016). Reduced goal-directed action control in autism spectrum disorder. Autism Research Published online: 21 March 2016 doi:10.1002/aur.1613.

APA (2013). Diagnostic and Statistical Manual of Mental Disorders, 5th edn. American Psychiatric Publishing: Arlington, VA.

Ball TM, Stein MB, Paulus MP (2014). Toward the application of functional neuroimaging to individualized treatment for anxiety and depression. Depression and Anxiety 31, 920-933.

Bates AT, Kiehl KA, Laurens KR, Liddle PF (2002). Error-related negativity and correct response negativity in schizophrenia. Clinical Neurophysiology 113, 1454-1463.

Bates AT, Liddle PF, Kiehl KA, Ngan ET (2004). State dependent changes in error monitoring in schizophrenia. Journal of Psychiatric Research 38, 347-356. 
Bloch MH, Landeros-Weisenberger A, Kelmendi B, Coric V, Bracken MB, Leckman JF (2006). A systematic review: antipsychotic augmentation with treatment refractory obsessive-compulsive disorder. Molecular Psychiatry 11, 622-632.

Brodersen KH, Deserno L, Schlagenhauf F, Lin Z, Penny WD, Buhmann JM, Stephan KE (2014). Dissecting psychiatric spectrum disorders by generative embedding. Neuroimage: Clinical 4, 98-111.

Brody AL, Saxena S, Schwartz JM, Stoessel PW, Maidment K, Phelps ME, Baxter LR (1998). FDG-PET predictors of response to behavioral therapy and pharmacotherapy in obsessive compulsive disorder. Psychiatry Research 84, 1-6.

Burgio-Murphy A, Klorman R, Shaywitz SE, Fletcher JM, Marchione KE, Holahan J, Stuebing KK, Thatcher JE, Shaywitz BA (2007). Error-related event-related potentials in children with attention-deficit hyperactivity disorder, oppositional defiant disorder, reading disorder, and math disorder. Biological Psychology 75, 75-86.

Carey PD, Warwick J, Niehaus DJ, van der Linden G, van Heerden BB, Harvey BH, Seedat S \& Stein DJ (2004). Single photon emission computed tomography (SPECT) of anxiety disorders before and after treatment with citalopram. BMC Psychiatry 4, 30.

Carrasco M, Harbin SM, Nienhuis JK, Fitzgerald KD, Gehring WJ, Hanna GL (2013a). Increased error-related brain activity in youth with obsessive-compulsive disorder and unaffected siblings. Depression and Anxiety 30, 39-46.

Carrasco M, Hong C, Nienhuis JK, Harbin SM, Fitzgerald KD, Gehring WJ, Hanna GL (2013b). Increased error-related brain activity in youth with obsessive-compulsive disorder and other anxiety disorders. Neuroscience Letters 541, 214-218.

Chen H, Jiang H, Guo Q, Du J, Wang J, Zhao M (2013). Case-control study of error-related negativity among males with heroin dependence undergoing rehabilitation. Shanghai Archives of Psychiatry 25, 141-148.

Chiu PH, Deldin PJ (2007). Neural evidence for enhanced error detection in major depressive disorder. American Journal of Psychiatry 164, 608-616.

Clemans ZA, El-Baz AS, Hollifield M, Sokhadze EM (2012). Single trial time-frequency domain analysis of error processing in post-traumatic stress disorder. Neuroscience Letters 525, 105-110.

Coles ME, Heimberg RG, Frost RO, Steketee G (2005). Not just right experiences and obsessive-compulsive features: experimental and self-monitoring perspectives. Behaviour, Research and Therapy 43, 153-167.

Cullen B, Brown CH, Riddle MA, Grados M, Bienvenu OJ, Hoehn-Saric R, Shugart YY, Liang KY, Samuels J, Nestadt G (2007). Factor analysis of the yale-brown obsessive compulsive scale in a family study of obsessive-compulsive disorder. Depression and Anxiety 24, 130-138.

Cushman F, Morris A (2015). Habitual control of goal selection in humans. Proceedings of the National Academy of Sciences of the United States of America 112, 13817-13822.

Cuthbert BN, Kozak MJ (2013). Constructing constructs for psychopathology: the NIMH research domain criteria. Journal of Abnormal Psychology 122, 928-937.
Davis JM, Giakas WJ, Qu J, Prasad P, Leucht S (2011). Should we treat depression with drugs or psychological interventions? A reply to Ioannidis. Philosophy, Ethics, and Humanities in Medicine 6, 8.

Daw ND, Gershman SJ, Seymour B, Dayan P, Dolan RJ (2011). Model-based influences on humans' choices and striatal prediction errors. Neuron 69, 1204-1215.

Debener S, Ullsperger M, Siegel M, Fiehler K, von Cramon DY, Engel AK (2005). Trial-by-trial coupling of concurrent electroencephalogram and functional magnetic resonance imaging identifies the dynamics of performance monitoring. Journal of Neuroscience 25, 11730-11737.

de Bruijn ER, Hulstijn W, Verkes RJ, Ruigt GS, Sabbe BG (2004). Drug-induced stimulation and suppression of action monitoring in healthy volunteers. Psychopharmacology (Berlin) 177, 151-160.

de Bruijn ER, Sabbe BG, Hulstijn W, Ruigt GS, Verkes RJ (2006). Effects of antipsychotic and antidepressant drugs on action monitoring in healthy volunteers. Brain Research 1105, 122-129.

de la Asuncion J, Docx L, Morrens M, Sabbe B, de Bruijn ER (2015). Neurophysiological evidence for diminished monitoring of own, but intact monitoring of other's errors in schizophrenia. Psychiatry Research 230, 220-226.

Delorme C, Salvador A, Palminteri S, de Wit S, Roze E, Hartmann A, Worbe Y (2015). Goal-directed and habitual behaviour systems in Gilles de la Tourette syndrome. Movement Disorders 30, S490-S490.

Delorme C, Salvador A, Valabrègue R, Roze E, Palminteri S, Vidailhet M, de Wit S, Robbins T, Hartmann A, Worbe $Y$ (2016). Enhanced habit formation in Gilles de la Tourette syndrome. Brain 139, 605-615.

Denys D, Mantione $M$, Figee $M$, van den Munckhof $P$, Koerselman F, Westenberg H, Bosch A, Schuurman R (2010). Deep brain stimulation of the nucleus accumbens for treatment-refractory obsessive-compulsive disorder. Archives of General Psychiatry 67, 1061-1068.

de Wit SJ, Alonso P, Schweren L, Mataix-Cols D, Lochner C, Menchón JM, Stein DJ, Fouche JP, Soriano-Mas C, Sato JR, Hoexter MQ, Denys D, Nakamae T, Nishida S, Kwon JS, Jang JH, Busatto GF, Cardoner N, Cath DC, Fukui K, Jung WH, Kim SN, Miguel EC, Narumoto J, Phillips ML, Pujol J, Remijnse PL, Sakai Y, Shin NY, Yamada K, Veltman DJ, van den Heuvel OA (2014). Multicenter voxel-based morphometry mega-analysis of structural brain scans in obsessive-compulsive disorder. American Journal of Psychiatry 171, 340-349.

Dickinson A (1985). Actions and habits: the development of behavioural autonomy. Philosophical Transactions of the Royal Society of London. Series B, Biological Sciences 308, 67-78.

Dolan RJ, Dayan P (2013). Goals and habits in the brain. Neuron 80, 312-325.

Ecker W, Gönner S (2008). Incompleteness and harm avoidance in OCD symptom dimensions. Behaviour, Research and Therapy 46, 895-904.

Endrass T, Klawohn J, Schuster F, Kathmann N (2008). Overactive performance monitoring in obsessive-compulsive disorder: ERP evidence from correct and erroneous reactions. Neuropsychologia 46, 1877-1887. 
Endrass T, Riesel A, Kathmann N, Buhlmann U (2014). Performance monitoring in obsessive-compulsive disorder and social anxiety disorder. Journal of Abnormal Psychology 123, 705-714.

Endrass T, Schuermann B, Kaufmann C, Spielberg R, Kniesche R, Kathmann N (2010). Performance monitoring and error significance in patients with obsessive-compulsive disorder. Biological Psychology $\mathbf{8 4}$ 257-263.

Endrass T, Ullsperger M (2014). Specificity of performance monitoring changes in obsessive-compulsive disorder. Neuroscience \& Biobehavioral Reviews 46, 124-138.

Ersche KD, Gillan CM, Jones PS, Williams GB, Luitjen M, de Wit S, Ward LHE, Sahakian BJ, Bullmore ET, Robbins TW (2016). Carrots and sticks fail to change behavior in cocaine addiction. Science 352, 1468-1471.

Everitt BJ, Dickinson A, Robbins TW (2001). The neuropsychological basis of addictive behaviour. Brain Research Reviews 36, 129-138.

Everitt BJ, Robbins TW (2005). Neural systems of reinforcement for drug addiction: from actions to habits to compulsion. Nature Neuroscience 8, 1481-1489.

Fair DA, Bathula D, Nikolas MA, Nigg JT (2012). Distinct neuropsychological subgroups in typically developing youth inform heterogeneity in children with ADHD. Proceedings of the National Academy of Sciences USA 109, 6769-6774.

Falkenstein M, Hohnsbein J, Hoormann J, Blanke L (1991). Effects of crossmodal divided attention on late ERP components. II. Error processing in choice reaction tasks. Electroencephalography and Clinical Neurophysiology 78, 447-455.

Fineberg NA, Chamberlain SR, Goudriaan AE, Stein DJ, Vanderschuren LJ, Gillan CM, Shekar S, Gorwood PA, Voon V, Morein-Zamir S, Denys D, Sahakian BJ, Moeller FG, Robbins TW, Potenza MN (2014). New developments in human neurocognition: clinical, genetic, and brain imaging correlates of impulsivity and compulsivity. CNS Spectrums 19, 69-89.

Fineberg NA, Hengartner MP, Bergbaum C, Gale T, Rössler W, Angst J (2013a). Lifetime comorbidity of obsessive-compulsive disorder and sub-threshold obsessive-compulsive symptomatology in the community: impact, prevalence, socio-demographic and clinical characteristics. International Journal of Psychiatry in Clinical Practice 17, 188-196.

Fineberg NA, Reghunandanan S, Brown A, Pampaloni I (2013b). Pharmacotherapy of obsessive-compulsive disorder: evidence-based treatment and beyond. Australian and New Zealand Journal of Psychiatry 47, 121-141.

Foa EB, Huppert JD, Leiberg S, Langner R, Kichic R, Hajcak G, Salkovskis P (2002). The obsessive-compulsive inventory: development and validation of a short version. Psychological Assessment 14, 485-496.

Forman SD, Dougherty GG, Casey BJ, Siegle GJ, Braver TS, Barch DM, Stenger VA, Wick-Hull C, Pisarov LA, Lorensen E (2004). Opiate addicts lack error-dependent activation of rostral anterior cingulate. Biological Psychiatry $55,531-537$
Foti D, Kotov R, Bromet E, Hajcak G (2012). Beyond the broken error-related negativity: functional and diagnostic correlates of error processing in psychosis. Biological Psychiatry 71, 864-872.

Frank MJ, Woroch BS, Curran T (2005). Error-related negativity predicts reinforcement learning and conflict biases. Neuron 47, 495-501.

Franken IH, van Strien JW, Franzek EJ, van de Wetering BJ (2007). Error-processing deficits in patients with cocaine dependence. Biological Psychology 75, 45-51.

Garner DM, Olmsted MP, Bohr Y, Garfinkel PE (1982). The eating attitudes test: psychometric features and clinical correlates. Psychological Medicine 12, 871-878.

Gehring WJ, Himle J, Nisenson LG (2000). Action-monitoring dysfunction in obsessive-compulsive disorder. Psychological Science 11, 1-6.

Georgiadi E, Liotti M, Nixon NL, Liddle PF (2011). Electrophysiological evidence for abnormal error monitoring in recurrent major depressive disorder. Psychophysiology 48, 1192-1202.

Geurts H, de Wit S (2013). Goal-directed action control in children with autism spectrum disorders. Autism 18, 409-418.

Gillan C, Daw N (2016). Taking psychiatry research online. Neuron 91, 19-23.

Gillan C, Kosinski M, Whelan R, Phelps E, Daw N (2016b). Characterizing a psychiatric symptom dimension related to deficits in goal-directed control. eLife 5, e11305.

Gillan C, Robbins T, Sahakian B, van den Heuvel O, van Wingen G (2016a). The role of habit in compulsivity. European Neuropsychopharmacology 5, 828-840.

Gillan CM, Apergis-Schoute AM, Morein-Zamir S, Urcelay GP, Sule A, Fineberg NA, Sahakian BJ, Robbins TW (2015a). Functional neuroimaging of avoidance habits in obsessive-compulsive disorder. American Journal of Psychiatry 172, 284-293.

Gillan CM, Morein-Zamir S, Kaser M, Fineberg NA, Sule A, Sahakian BJ, Cardinal RN, Robbins TW (2014a). Counterfactual processing of economic action-outcome alternatives in obsessive-compulsive disorder: further evidence of impaired goal-directed behavior. Biological Psychiatry 75, 639-646.

Gillan CM, Morein-Zamir S, Urcelay GP, Sule A, Voon V, Apergis-Schoute AM, Fineberg NA, Sahakian BJ \& Robbins TW (2014b). Enhanced avoidance habits in obsessive-compulsive disorder. Biological Psychiatry 75, 631-638.

Gillan CM, Otto AR, Phelps EA, Daw ND (2015b). Model-based learning protects against forming habits. Cognitive Affective and Behavioral Neuroscience 15, 523-536.

Gillan CM, Papmeyer M, Morein-Zamir S, Sahakian BJ, Fineberg NA, Robbins TW, de Wit S (2011). Disruption in the balance between goal-directed behavior and habit learning in obsessive-compulsive disorder. American Journal of Psychiatry 168, 718-726.

Gillan CM, Robbins TW (2014). Goal-directed learning and obsessive-compulsive disorder. Philosophical Transactions of the Royal Society London, Series B: Biological Sciences 369, 20130475. 
Gillan CM, Sahakian BJ (2015). Which is the driver, the obsessions or the compulsions, in OCD? Neuropsychopharmacology 40, 247-248.

Godier LR, Park RJ (2014). Compulsivity in anorexia nervosa: a transdiagnostic concept. Frontiers in Psychology 5, 778.

Goschke T (2014). Dysfunctions of decision-making and cognitive control as transdiagnostic mechanisms of mental disorders: advances, gaps, and needs in current research. International Journal of Methods in Psychiatric Research 23, 41-57.

Grant BF, Hasin DS, Blanco C, Stinson FS, Chou SP, Goldstein RB, Dawson DA, Smith S, Saha TD, Huang B (2005). The epidemiology of social anxiety disorder in the United States: results from the National Epidemiologic Survey on Alcohol and Related Conditions. Journal of Clinical Psychiatry 66, 1351-1361.

Graybiel AM (1998). The basal ganglia and chunking of action repertoires. Neurobiology of Learning and Memory 70, 119-136.

Graybiel AM, Rauch SL (2000). Toward a neurobiology of obsessive-compulsive disorder. Neuron 28, 343-347.

Greenberg BD, Gabriels LA, Malone DA, Rezai AR, Friehs GM, Okun MS, Shapira NA, Foote KD, Cosyns PR, Kubu CS, Malloy PF, Salloway SP, Giftakis JE, Rise MT, Machado AG, Baker KB, Stypulkowski PH, Goodman WK, Rasmussen SA, Nuttin BJ (2010). Deep brain stimulation of the ventral internal capsule/ventral striatum for obsessive-compulsive disorder: worldwide experience. Molecular Psychiatry 15, 64-79.

Groen Y, Wijers AA, Mulder LJ, Waggeveld B, Minderaa RB, Althaus M (2008). Error and feedback processing in children with ADHD and children with Autistic Spectrum Disorder: an EEG event-related potential study. Clinical Neurophysiology 119, 2476-2493.

Groenewegen HJ, van den Heuvel OA, Cath DC, Voorn P, Veltman DJ (2003). Does an imbalance between the dorsal and ventral striatopallidal systems play a role in Tourette's syndrome? A neuronal circuit approach. Brain and Development 25 (Suppl. 1), S3-S14.

Groom MJ, Cahill JD, Bates AT, Jackson GM, Calton TG, Liddle PF, Hollis C (2010). Electrophysiological indices of abnormal error-processing in adolescents with attention deficit hyperactivity disorder (ADHD). Journal of Child Psychology and Psychiatry 51, 66-76.

Groom MJ, Liddle EB, Scerif G, Liddle PF, Batty MJ, Liotti M, Hollis CP (2013). Motivational incentives and methylphenidate enhance electrophysiological correlates of error monitoring in children with attention deficit/ hyperactivity disorder. Journal of Child Psychology and Psychiatry 54, 836-845.

Grützmann R, Endrass T, Kaufmann C, Allen E, Eichele T, Kathmann N (2014). Presupplementary motor area contributes to altered error monitoring in obsessivecompulsive disorder. Biological Psychiatry 80, 562-571.

Hajcak G, Foti D (2008). Errors are aversive: defensive motivation and the error-related negativity. Psychological Science 19, 103-108.

Hajcak G, Franklin ME, Foa EB, Simons RF (2008). Increased error-related brain activity in pediatric obsessive-compulsive disorder before and after treatment. American Journal of Psychiatry 165, 116-123.

Hajcak G, McDonald N, Simons RF (2003). Anxiety and error-related brain activity. Biological Psychology 64, 77-90.

Hajcak G, Simons RF (2002). Error-related brain activity in obsessive-compulsive undergraduates. Psychiatry Research 110, 63-72.

Hanna GL, Carrasco M, Harbin SM, Nienhuis JK, LaRosa CE, Chen P, Fitzgerald KD, Gehring WJ (2012).

Error-related negativity and tic history in pediatric obsessive-compulsive disorder. Journal of the American Academy of Child and Adolescent Psychiatry 51, 902-910.

Henderson HA, Ono KE, McMahon CM, Schwartz CB, Usher LV, Mundy PC (2015). The costs and benefits of self-monitoring for higher functioning children and adolescents with autism. Journal of Autism and Developmental Disorders 45, 548-559.

Herrmann MJ, Mader K, Schreppel T, Jacob C, Heine M, Boreatti-Hümmer A, Ehlis AC, Scheuerpflug P, Pauli P, Fallgatter AJ (2010). Neural correlates of performance monitoring in adult patients with attention deficit hyperactivity disorder (ADHD). World Journal of Biological Psychiatry 11, 457-464.

Hoexter MQ, Diniz JB, Lopes AC, Batistuzzo MC, Shavitt RG, Dougherty DD, Duran FL, Bressan RA, Busatto GF, Miguel EC, Sato JR (2015). Orbitofrontal thickness as measure for treatment response prediction in obsessive-compulsive disorder. Depression and Anxiety 32, 900-908.

Hoexter MQ, Dougherty DD, Shavitt RG, D'Alcante CC, Duran FL, Lopes AC, Diniz JB, Batistuzzo MC, Evans KC, Bressan RA, Busatto GF, Miguel EC (2013). Differential prefrontal gray matter correlates of treatment response to fluoxetine or cognitive-behavioral therapy in obsessivecompulsive disorder. European Neuropsychopharmacology 23, 569-580.

Hogarth L, Chase H, Baess K (2012). Impaired goal-directed behavioural control in human impulsivity. Quarterly Journal of Experimental Psychology 65, 305-316.

Hollander E, Kaplan A, Stahl SM (2003). A double-blind, placebo-controlled trial of clonazepam in obsessive-compulsive disorder. World Journal of Biological Psychiatry 4, 30-34.

Holmes AJ, Pizzagalli DA (2008). Spatiotemporal dynamics of error processing dysfunctions in major depressive disorder. Archives of General Psychiatry 65, 179-188.

Holmes AJ, Pizzagalli DA (2010). Effects of task-relevant incentives on the electrophysiological correlates of error processing in major depressive disorder. Cognitive Affective Behavior and Neuroscience 10, 119-128.

Holroyd CB, Coles MG (2002). The neural basis of human error processing: reinforcement learning, dopamine, and the error-related negativity. Psychological Reviews 109, 679-709.

Ho Pian KL, van Megen HJ, Ramsey NF, Mandl R, van Rijk PP, Wynne HJ, Westenberg HG (2005). Decreased thalamic blood flow in obsessive-compulsive disorder patients responding to fluvoxamine. Psychiatry Research 138, 89-97. 
Horan WP, Foti D, Hajcak G, Wynn JK, Green MF (2012). Impaired neural response to internal but not external feedback in schizophrenia. Psychological Medicine 42, 1637-1647.

Houthoofd S, Morrens M, Sabbe B, Schrijvers D, Vandendriessche F, Hulstijn W, de Bruijn ER (2013). Trait and state aspects of internal and external performance monitoring in schizophrenia. International Journal of Psychophysiology 87, 42-51.

Hyman SE (2007). Can neuroscience be integrated into the DSM-V? Nature Reviews Neuroscience 8, 725-732.

Hyman SE (2010). The diagnosis of mental disorders: the problem of reification. Annual Review of Clinical Psychology 6, 155-179.

Iervolino AC, Rijsdijk FV, Cherkas L, Fullana MA, Mataix-Cols D (2011). A multivariate twin study of obsessive-compulsive symptom dimensions. Archives of General Psychiatry 68, 637-644.

Insel T, Cuthbert B, Garvey M, Heinssen R, Pine DS, Quinn K, Sanislow C, Wang P (2010). Research domain criteria (RDoC): toward a new classification framework for research on mental disorders. American Journal of Psychiatry 167, 748-751.

Jacob ML, Larson MJ, Storch EA (2014). Insight in adults with obsessive-compulsive disorder. Comprehensive Psychiatry 55, 896-903.

Johannes S, Wieringa BM, Nager W, Dengler R, Münte TF (2001a). Oxazepam alters action monitoring. Psychopharmacology (Berlin) 155, 100-106.

Johannes S, Wieringa BM, Nager W, Rada D, Dengler R, Emrich HM, Münte TF, Dietrich DE (2001b). Discrepant target detection and action monitoring in obsessivecompulsive disorder. Psychiatry Research 108, 101-110.

Jonkman LM, van Melis JJ, Kemner C, Markus CR (2007). Methylphenidate improves deficient error evaluation in children with ADHD: an event-related brain potential study. Biological Psychology 76, 217-229.

Kansal V, Patriciu I, Kiang M (2014). Illness insight and neurophysiological error-processing deficits in schizophrenia. Schizophrenia Research 156, 122-127.

Klawohn J, Riesel A, Grützmann R, Kathmann N, Endrass T (2014). Performance monitoring in obsessive-compulsive disorder: a temporo-spatial principal component analysis. Cognitive Affective and Behavioral Neuroscience 14, 983-995.

Kopf J, Volkert J, Heidler S, Dresler T, Kittel-Schneider S, Gessner A, Herrmann MJ, Ehlis AC, Reif A (2015). Electrophysiological evidence of a typical cognitive distortion in bipolar disorder. Cortex 66, 103-114.

Kopp B, Rist F (1999). An event-related brain potential substrate of disturbed response monitoring in paranoid schizophrenic patients. Journal of Abnormal Psychology 108, 337-346.

Ladouceur CD, Dahl RE, Birmaher B, Axelson DA, Ryan ND (2006). Increased error-related negativity (ERN) in childhood anxiety disorders: ERP and source localization. Journal of Child Psychology and Psychiatry 47, 1073-1082.

Ladouceur CD, Slifka JS, Dahl RE, Birmaher B, Axelson DA, Ryan ND (2012). Altered error-related brain activity in youth with major depression. Developmental Cognitive Neuroscience 2, 351-362.
Leucht S, Helfer B, Gartlehner G, Davis JM (2015). How effective are common medications: a perspective based on meta-analyses of major drugs. BMC Medicine 13, 253.

Liebowitz MR (1987). Social phobia. Modern Problems of Pharmacopsychiatry 22, 141-173.

Liotti M, Pliszka SR, Perez R, Kothmann D, Woldorff MG (2005). Abnormal brain activity related to performance monitoring and error detection in children with ADHD. Cortex 41, 377-388.

Lipszyc J, Schachar R (2010). Inhibitory control and psychopathology: a meta-analysis of studies using the stop signal task. Journal of the International Neuropsycholical Society 16, 1064-1076.

Liu Y, Hanna GL, Carrasco M, Gehring WJ, Fitzgerald KD (2014). Altered relationship between electrophysiological response to errors and gray matter volumes in an extended network for error-processing in pediatric obsessivecompulsive disorder. Human Brain Mapping 35, 1143-1153.

Logan G (1994). On the ability to inhibit thought and action: a user's guide to the stop signal paradigm. In Inhibitory Processes in Attention, Memory and Language (ed. D. Dagenbach and T. H. Carr), pp. 189-239. Academic: San Diego.

Lovinger DM (2010). Neurotransmitter roles in synaptic modulation, plasticity and learning in the dorsal striatum. Neuropharmacology 58, 951-961.

Luijten M, van Meel CS, Franken IH (2011). Diminished error processing in smokers during smoking cue exposure. Pharmacology Biochemistry and Behavior 97, 514-520.

Mallet L, Polosan M, Jaafari N, Baup N, Welter ML, Fontaine D, du Montcel ST, Yelnik J, Chéreau I, Arbus C, Raoul S, Aouizerate B, Damier $P$, Chabardès $S$, Czernecki V, Ardouin C, Krebs MO, Bardinet E, Chaynes P, Burbaud P, Cornu P, Derost P, Bougerol T, Bataille B, Mattei V, Dormont D, Devaux B, Vérin $M$, Houeto JL, Pollak P, Benabid AL, Agid Y, Krack P, Millet B, Pelissolo A, Group SS (2008). Subthalamic nucleus stimulation in severe obsessive-compulsive disorder. New England Journal of Medicine 359, 2121-2134.

Marin RS, Biedrzycki RC, Firinciogullari S (1991). Reliability and validity of the apathy evaluation scale. Psychiatry Research 38, 143-162.

Mason O, Linney Y, Claridge G (2005). Short scales for measuring schizotypy. Schizophrenia Research 78, 293-296.

Mataix-Cols D, Rauch SL, Manzo PA, Jenike MA, Baer L (1999). Use of factor-analyzed symptom dimensions to predict outcome with serotonin reuptake inhibitors and placebo in the treatment of obsessive-compulsive disorder. American Journal of Psychiatry 156, 1409-1416.

Mataix-Cols D, Rosario-Campos MC, Leckman JF (2005). A multidimensional model of obsessive-compulsive disorder American Journal of Psychiatry 162, 228-238.

Mathalon DH, Jorgensen KW, Roach BJ, Ford JM (2009). Error detection failures in schizophrenia: ERPs and FMRI. International Journal of Psychophysiology 73, 109-117.

Mathews CA, Perez VB, Roach BJ, Fekri S, Vigil O, Kupferman E, Mathalon DH (2015). Error-related brain activity dissociates hoarding disorder from obsessivecompulsive disorder. Psychological Medicine 46, 367-379. 
Minzenberg MJ, Gomes GC, Yoon JH, Swaab TY, Carter CS (2014). Disrupted action monitoring in recent-onset psychosis patients with schizophrenia and bipolar disorder. Psychiatry Research 221, 114-121.

Morris RW, Quail S, Griffiths KR, Green MJ, Balleine BW (2015). Corticostriatal control of goal-directed action is impaired in Schizophrenia. Biological Psychiatry 77, 187-195.

Morris SE, Heerey EA, Gold JM, Holroyd CB (2008). Learning-related changes in brain activity following errors and performance feedback in schizophrenia. Schizophrenia Research 99, 274-285.

Morris SE, Holroyd CB, Mann-Wrobel MC, Gold JM (2011). Dissociation of response and feedback negativity in schizophrenia: electrophysiological and computational evidence for a deficit in the representation of value. Frontiers in Human Neuroscience 5, 123.

Morris SE, Yee CM \& Nuechterlein KH (2006). Electrophysiological analysis of error monitoring in schizophrenia. Journal of Abnormal Psychology 115, 239-250.

Morsel AM, Morrens M, Temmerman A, Sabbe B, de Bruijn ER (2014). Electrophysiological (EEG) evidence for reduced performance monitoring in euthymic bipolar disorder. Bipolar Disorder 16, 820-829.

Mueller EM, Pechtel P, Cohen AL, Douglas SR, Pizzagalli DA (2015). Potentiated processing of negative feedback in depression is attenuated by anhedonia. Depression and Anxiety 32, 296-305.

Nestadt G, Di CZ, Riddle MA, Grados MA, Greenberg BD, Fyer AJ, McCracken JT, Rauch SL, Murphy DL, Rasmussen SA, Cullen B, Pinto A, Knowles JA, Piacentini J, Pauls DL, Bienvenu OJ, Wang Y, Liang KY, Samuels JF, Roche KB (2009). Obsessive-compulsive disorder: subclassification based on co-morbidity. Psychological Medicine 39, 1491-1501.

Nieuwenhuis S, Nielen MM, Mol N, Hajcak G, Veltman DJ (2005). Performance monitoring in obsessive-compulsive disorder. Psychiatry Research 134, 111-122.

Nuttin BJ, Gabriëls LA, Cosyns PR, Meyerson BA, Andréewitch S, Sunaert SG, Maes AF, Dupont PJ, Gybels JM, Gielen F, Demeulemeester HG (2008). Long-term electrical capsular stimulation in patients with obsessive-compulsive disorder. Neurosurgery 62, 966-977.

Olvet DM, Klein DN, Hajcak G (2010). Depression symptom severity and error-related brain activity. Psychiatry Research 179, 30-37.

Otto AR, Gershman SJ, Markman AB, Daw ND (2013). the curse of planning: dissecting multiple reinforcementlearning systems by taxing the central executive. Psychological Science 24, 751-761.

Pallanti S, Grassi G, Sarrecchia ED, Cantisani A, Pellegrini M (2011). Obsessive-compulsive disorder comorbidity: clinical assessment and therapeutic implications. Frontiers in Psychiatry 2, 70.

Patton JH, Stanford MS, Barratt ES (1995). Factor structure of the Barratt impulsiveness scale. Journal of Clinical Psychology 51, 768-774.

Paulus MP, Feinstein JS, Simmons A, Stein MB (2004). Anterior cingulate activation in high trait anxious subjects is related to altered error processing during decision making. Biological Psychiatry 55, 1179-1187.

Perez VB, Ford JM, Roach BJ, Woods SW, McGlashan TH, Srihari VH, Loewy RL, Vinogradov S, Mathalon DH (2012). Error monitoring dysfunction across the illness course of schizophrenia. Journal of Abnormal Psychology 121, 372-387.

Potts GF, George MR, Martin LE, Barratt ES (2006). Reduced punishment sensitivity in neural systems of behavior monitoring in impulsive individuals. Neuroscience Letters 397, 130-134.

Pujol J, Soriano-Mas C, Alonso P, Cardoner N, Menchon JM, Deus J, Vallejo J (2004). Mapping structural brain alterations in obsessive-compulsive disorder. Archives of General Psychiatry 61, 720-730.

Rabinak CA, Holman A, Angstadt M, Kennedy AE, Hajcak G, Phan KL (2013). Neural response to errors in combat-exposed returning veterans with and without post-traumatic stress disorder: a preliminary event-related potential study. Psychiatry Research 213, 71-78.

Rachman S, de Silva P (1978). Abnormal and normal obsessions. Behaviour, Research and Therapy 16, 233-248.

Ravindran LN, Stein MB (2010). The pharmacologic treatment of anxiety disorders: a review of progress. Journal of Clinical Psychiatry 71, 839-854.

Regier DA, Narrow WE, Clarke DE, Kraemer HC, Kuramoto SJ, Kuhl EA, Kupfer DJ (2013). DSM-5 field trials in the United States and Canada, Part II: test-retest reliability of selected categorical diagnoses. American Journal of Psychiatry 170, 59-70.

Reinhart RM, Zhu J, Park S, Woodman GF (2015). Medial-frontal stimulation enhances learning in schizophrenia by restoring prediction error signaling. Journal of Neuroscience 35, 12232-12240.

Riba J, Rodríguez-Fornells A, Münte TF, Barbanoj MJ (2005). A neurophysiological study of the detrimental effects of alprazolam on human action monitoring. Brain Research Cognitive Brain Research 25, 554-565.

Riesel A, Endrass T, Auerbach LA, Kathmann N (2015). overactive performance monitoring as an endophenotype for obsessive-compulsive disorder: evidence from a treatment study. American Journal of Psychiatry 172, 665-673.

Riesel A, Endrass T, Kaufmann C, Kathmann N (2011). Overactive error-related brain activity as a candidate endophenotype for obsessive-compulsive disorder: evidence from unaffected first-degree relatives. American Journal of Psychiatry 168, 317-324.

Robbins TW, Gillan CM, Smith DG, de Wit S, Ersche KD (2012). Neurocognitive endophenotypes of impulsivity and compulsivity: towards dimensional psychiatry. Trends in Cognitive Sciences 16, 81-91.

Rosenthal R (1979). The file drawer problem and tolerance for null results. Psychological Bulletin 86, 638-641.

Ruchsow M, Gron G, Reuter K, Spitzer M, Hermle L, Kiefer M (2005). Error-related brain activity in patients with obsessive compulsive disorder and in healthy controls. Journal of Psychophysiology 19, 298-304.

Ruchsow M, Herrnberger B, Beschoner P, Grön G, Spitzer M, Kiefer M (2006). Error processing in major depressive 
disorder: evidence from event-related potentials. Journal of Psychiatry Research 40, 37-46.

Ruchsow M, Herrnberger B, Wiesend C, Grön G, Spitzer M, Kiefer M (2004). The effect of erroneous responses on response monitoring in patients with major depressive disorder: a study with event-related potentials.

Psychophysiology 41, 833-840.

Ruchsow M, Reuter K, Hermle L, Ebert D, Kiefer M, Falkenstein M (2007). Executive control in obsessivecompulsive disorder: event-related potentials in a Go/Nogo task. Journal of Neural Transmission 114, 1595-1601.

Ruscio AM, Stein DJ, Chiu WT, Kessler RC (2010). The epidemiology of obsessive-compulsive disorder in the National Comorbidity Survey Replication. Molecular Psychiatry 15, 53-63.

Salkovskis PM (1985). Obsessional-compulsive problems: a cognitive-behavioural analysis. Behaviour, Research and Therapy 23, 571-583.

Sanislow CA, Pine DS, Quinn KJ, Kozak MJ, Garvey MA, Heinssen RK, Wang PS, Cuthbert BN (2010). Developing constructs for psychopathology research: research domain criteria. Journal of Abnormal Psychology 119, 631-639.

Saunders JB, Aasland OG, Babor TF, de la Fuente JR, Grant M (1993). Development of the alcohol use disorders identification test (AUDIT): WHO collaborative project on early detection of persons with harmful alcohol consumption-II. Addiction 88, 791-804.

Saxena S, Brody AL, Ho ML, Zohrabi N, Maidment KM, Baxter LR (2003). Differential brain metabolic predictors of response to paroxetine in obsessive-compulsive disorder versus major depression. American Journal of Psychiatry 160, 522-532.

Saxena S, Brody AL, Maidment KM, Dunkin JJ, Colgan M, Alborzian S, Phelps ME, Baxter LR (1999). Localized orbitofrontal and subcortical metabolic changes and predictors of response to paroxetine treatment in obsessive-compulsive disorder. Neuropsychopharmacology 21, 683-693.

Saxena S, Gorbis E, O'Neill J, Baker SK, Mandelkern MA, Maidment KM, Chang S, Salamon N, Brody AL, Schwartz JM, London ED (2009). Rapid effects of brief intensive cognitive-behavioral therapy on brain glucose metabolism in obsessive-compulsive disorder. Molecular Psychiatry 14, 197-205.

Schellekens AF, de Bruijn ER, van Lankveld CA, Hulstijn W, Buitelaar JK, de Jong CA, Verkes RJ (2010). Alcohol dependence and anxiety increase error-related brain activity. Addiction 105, 1928-1934.

Schwabe L, Wolf OT (2009). Stress prompts habit behavior in humans. Journal of Neuroscience 29, 7191-7198.

Simmonite M, Bates AT, Groom MJ, Jackson GM, Hollis C, Liddle PF (2012). Error processing-associated event-related potentials in schizophrenia and unaffected siblings. International Journal of Psychophysiology 84, 74-79.

Sjoerds Z, de Wit S, van den Brink W, Robbins TW, Beekman AT, Penninx BW, Veltman DJ (2013). Behavioral and neuroimaging evidence for overreliance on habit learning in alcohol-dependent patients. Translational Psychiatry 3, e337.
Snider LA, Swedo SE (2003). Childhood-onset obsessive-compulsive disorder and tic disorders: case report and literature review. Journal of Child and Adolescent Psychopharmacology 13 (Suppl. 1), S81-S88.

Snorrason I, Berlin GS, Lee HJ (2015). Optimizing psychological interventions for trichotillomania (hair-pulling disorder): an update on current empirical status. Psychology Research and Behavior Management 8, 105-113.

Snorrason I, Lee HJ, de Wit S, Woods DW (2016). Are nonclinical obsessive-compulsive symptoms associated with bias toward habits? Psychiatry Research 241, 221-223.

Sokhadze E, Baruth J, El-Baz A, Horrell T, Sokhadze G, Carroll T, Tasman A, Sears L, Casanova MF (2010). Impaired error monitoring and correction function in autism. Journal of Neurotherapy 14, 79-95.

Sokhadze E, Stewart C, Hollifield M, Tasman A (2008). Event-related potential study of executive dysfunctions in a speeded reaction task in cocaine addiction. Journal of Neurotherapy 12, 185-204.

Sokhadze EM, Baruth JM, Sears L, Sokhadze GE, El-Baz AS, Williams E, Klapheke R, Casanova MF (2012). Event-related potential study of attention regulation during illusory figure categorization task in ADHD, autism spectrum disorder, and typical children. Journal of Neurotherapy 16, 12-31.

Soomro GM, Altman D, Rajagopal S, Oakley-Browne M (2008). Selective serotonin re-uptake inhibitors (SSRIs) versus placebo for obsessive compulsive disorder (OCD). Cochrane Database of Systematic Reviews, CD001765.

South M, Larson MJ, Krauskopf E, Clawson A (2010). Error processing in high-functioning Autism Spectrum Disorders. Biological Psychology 85, 242-251.

Spielberger CD, Gorsuch RL, Lushene R, Vagg PR, Jacobs GA (1983). Manual for the State-Trait Anxiety Inventory. Consulting Psychologists Press: Palo Alto, CA.

Steele VR, Fink BC, Maurer JM, Arbabshirani MR, Wilber CH, Jaffe AJ, Sidz A, Pearlson GD, Calhoun VD, Clark VP, Kiehl KA (2014). Brain potentials measured during a Go/NoGo task predict completion of substance abuse treatment. Biological Psychiatry 76, 75-83.

Stern ER, Liu Y, Gehring WJ, Lister JJ, Yin G, Zhang J, Fitzgerald KD, Himle JA, Abelson JL, Taylor SF (2010). Chronic medication does not affect hyperactive error responses in obsessive-compulsive disorder. Psychophysiology 47, 913-920.

Swedo SE, Pietrini P, Leonard HL, Schapiro MB, Rettew DC, Goldberger EL, Rapoport SI, Rapoport JL, Grady CL (1992). Cerebral glucose metabolism in childhood-onset obsessive-compulsive disorder. Revisualization during pharmacotherapy. Archives of General Psychiatry 49, 690-694.

Swedo SE, Schapiro MB, Grady CL, Cheslow DL, Leonard HL, Kumar A, Friedland R, Rapoport SI, Rapoport JL (1989). Cerebral glucose metabolism in childhood-onset obsessive-compulsive disorder. Archives of General Psychiatry 46, 518-523.

Swets M, Dekker J, van Emmerik-van Oortmerssen K, Smid GE, Smit F, de Haan L, Schoevers RA (2014). The obsessive 
compulsive spectrum in schizophrenia, a meta-analysis and meta-regression exploring prevalence rates. Schizophrenia Research 152, 458-468.

Tang Y, Zhang X, Simmonite M, Li H, Zhang T, Guo Q, Li C, Fang Y, Xu Y, Wang J (2013). Hyperactivity within an extensive cortical distribution associated with excessive sensitivity in error processing in unmedicated depression: a combined event-related potential and sLORETA study. International Journal of Psychophysiology 90, 282-289.

Thase ME, Larsen KG, Kennedy SH (2011). Assessing the 'true' effect of active antidepressant therapy v. placebo in major depressive disorder: use of a mixture model. British Journal of Psychiatry 199, 501-507.

Torres AR (2016). The road to improvement in obsessive-compulsive disorder. Lancet Psychiatry 3, 695-697.

Torres AR, Fontenelle LF, Shavitt RG, Ferrão YA, do Rosário MC, Storch EA, Miguel EC (2016). Comorbidity variation in patients with obsessive-compulsive disorder according to symptom dimensions: results from a large multicentre clinical sample. Journal of Affective Disorders 190, 508-516.

van den Heuvel OA, Remijnse PL, Mataix-Cols D, Vrenken $\mathrm{H}$, Groenewegen HJ, Uylings HB, van Balkom AJ, Veltman DJ (2009). The major symptom dimensions of obsessive-compulsive disorder are mediated by partially distinct neural systems. Brain 132, 853-868.

van der Wee NJ, Ramsey NF, van Megen HJ, Denys D, Westenberg HG, Kahn RS (2007). Spatial working memory in obsessive-compulsive disorder improves with clinical response: a functional MRI study. European Neuropsychopharmacology 17, 16-23.

van Grootheest DS, Boomsma DI, Hettema JM, Kendler KS (2008). Heritability of obsessive-compulsive symptom dimensions. American Journal of Medical Genetics B Neuropsychiatric Genetics 147B, 473-478.

van Meel CS, Heslenfeld DJ, Oosterlaan J, Sergeant JA (2007). Adaptive control deficits in attention-deficit/ hyperactivity disorder (ADHD): the role of error processing. Psychiatry Research 151, 211-220.

Vlamings PH, Jonkman LM, Hoeksma MR, van Engeland H, Kemner C (2008). Reduced error monitoring in children with autism spectrum disorder: an ERP study. European Journal of Neuroscience 28, 399-406.

Voon V, Derbyshire K, Rück C, Irvine MA, Worbe $Y$, Enander J, Schreiber LR, Gillan C, Fineberg NA, Sahakian BJ, Robbins TW, Harrison NA, Wood J, Daw ND, Dayan P, Grant JE, Bullmore ET (2014). Disorders of compulsivity: a common bias towards learning habits. Molecular Psychiatry 20, 345-352.
Weinberg A, Klein DN, Hajcak G (2012). Increased error-related brain activity distinguishes generalized anxiety disorder with and without comorbid major depressive disorder. Journal of Abnormal Psychology 121, 885-896.

Weinberg A, Kotov R, Proudfit GH (2015). Neural indicators of error processing in generalized anxiety disorder, obsessive-compulsive disorder, and major depressive disorder. Journal of Abnormal Psychology 124, 172-185.

Weinberg A, Olvet DM, Hajcak G (2010). Increased error-related brain activity in generalized anxiety disorder. Biological Psychology 85, 472-480.

Wiersema JR, van der Meere JJ, Roeyers H (2005). ERP correlates of impaired error monitoring in children with ADHD. Journal of Neural Transmission 112, 1417-1430.

Wiersema JR, van der Meere JJ, Roeyers H (2009). ERP correlates of error monitoring in adult ADHD. Journal of Neural Transmission 116, 371-379.

Wild-Wall N, Oades RD, Schmidt-Wessels M, Christiansen H, Falkenstein M (2009). Neural activity associated with executive functions in adolescents with attention-deficit/ hyperactivity disorder (ADHD). International Journal of Psychophysiology 74, 19-27.

Xiao Z, Wang J, Zhang M, Li H, Tang Y, Wang Y, Fan Q, Fromson JA (2011). Error-related negativity abnormalities in generalized anxiety disorder and obsessive-compulsive disorder. Progress in Neuropsychopharmacology and Biological Psychiatry 35, 265-272.

Yeung N, Botvinick MM, Cohen JD (2004). The neural basis of error detection: conflict monitoring and the error-related negativity. Psychological Review 111, 931-959.

Zambrano-Vazquez L, Allen JJ (2014). Differential contributions of worry, anxiety, and obsessive compulsive symptoms to ERN amplitudes in response monitoring and reinforcement learning tasks. Neuropsychologia 61, 197-209.

Zhang JS, Wang Y, Cai RG, Yan CH (2009). The brain regulation mechanism of error monitoring in impulsive children with ADHD-an analysis of error related potentials. Neuroscience Letters 460, 11-15.

Zhou Z, Li C, Zhu H (2013). An error-related negativity potential investigation of response monitoring function in individuals with internet addiction disorder. Frontiers in Behavioral Neuroscience 7, 131.

Zirnheld PJ, Carroll CA, Kieffaber PD, O'Donnell BF, Shekhar A, Hetrick WP (2004). Haloperidol impairs learning and error-related negativity in humans. Journal of Cognitive Neuroscience 16, 1098-1112.

Zung WW (1965). A self-rating depression scale. Archives of General Psychiatry 12, 63-70. 